\title{
1 The Hsp90 chaperone system from the African trypanosome, 2 Trypanosoma brucei
}

3

4 Miebaka Jamabo ${ }^{1 \uparrow}$, Stephen J. Bentley ${ }^{1 \uparrow}$, Paula Macucule-Tinga ${ }^{1}$, Adrienne L. Edkins ${ }^{2}$ Aileen 5 Boshoff $^{1^{*}}$.

6

$7 \quad{ }^{1}$ Biotechnology Innovation Centre, Rhodes University, Makhanda/Grahamstown, South Africa

$8{ }^{2}$ Biomedical Biotechnology Research Unit (BioBRU), Department of Biochemistry and Microbiology, Rhodes

9 University, Makhanda/Grahamstown, South Africa

\section{* Corresponding author}

I These authors contributed equally to this work. 
26

27

\section{Abstract}

African Trypanosomiasis is a neglected tropical disease caused by Trypanosoma brucei (T. brucei) and is spread by the tsetse fly in sub-Saharan Africa. The disease is fatal if left untreated and the currently approved drugs for treatment are toxic and difficult to administer. The trypanosome must survive in the insect vector and its mammalian host, and to adapt to these different conditions, the parasite relies on molecular chaperones called heat shock proteins. Heat shock proteins mediate the folding of newly synthesized proteins as well as prevent misfolding of proteins under normal conditions and during stressful conditions. Heat shock protein 90 (Hsp90) is one of the major molecular chaperones of the stress response at the cellular level. It functions with other chaperones and co-chaperones and inhibition of its interactions is being explored as a potential therapeutic target for numerous diseases. This study provides an in-silico overview of Hsp90 and its co-chaperones in both T. brucei brucei and T. brucei gambiense in relation to human and other kinetoplastid parasites. The evolutionary, functional, and structural analyses of Hsp90 were also shown. The updated information on Hsp90 and its co-chaperones from recently published proteomics on $T$. brucei was examined for the different life cycle stages and subcellular localisations. The results show a difference between T. b. brucei and T. b. gambiense with T. b. brucei encoding 12 putative $H s p 90$ genes, 10 of which are cytosolic and located on a single chromosome while T. gambiense encodes 5 Hsp 90 genes, 3 of which are located in the cytosol. Eight putative co-chaperones were identified in this study, 6 TPR-containing and 2 non-TPR-containing cochaperones. This study provides an updated context for studying the biology of the African trypanosome and evaluating Hsp90 and its interactions as potential drug targets. 
Trypanosoma brucei (T. brucei), is an extracellular blood- and tissue-borne protozoan parasite transmitted by tsetse fly vectors, which causes devastating diseases in humans, wild animals and domesticated livestock (1). Human African trypanosomiasis (HAT, although known as African sleeping sickness), is a potentially fatal tropical disease found in remote rural regions of sub-Saharan Africa and often coincides with insubstantial health care systems (2). HAT is caused by two subspecies of $T$. brucei; The chronic form of the disease, which is endemic to Central and Western Africa, is caused by Trypanosoma brucei (T. b.) gambiense, and the acute zoonotic form, which is endemic to Eastern and Southern Africa, is caused by $T$. $b$. rhodesiense $(3,4)$. The livestock disease Nagana, caused by $T$. $b$. brucei also has a crippling effect on the socioeconomic development within sub-Saharan Africa $(5,6)$. Despite the decreasing number of HAT cases, there is still a desperate need for the development of new and more effective drugs due to the difficult administration and toxicity of the current treatments, lack of a vaccine and increasing parasite resistance (7). Molecular chaperones have been identified as an attractive target for drug development against protozoan parasites as this protein family plays essential roles in stress-induced stage differentiation and are vital for disease progression and transmission (810).

The 90-kDa heat shock protein (Hsp90) family contains essential, highly conserved and abundant molecular chaperones (11-13) that facilitate the proper folding and maturation of a large but specific group of substrates called client proteins (14-16). More than 400 client proteins have been identified to date (listed at http://www.picard.ch/), with many of them being implicated in protein folding and degradation, signalling pathways, cellular trafficking, cell cycle regulation, differentiation, and others (17-19). In eukaryotes, the Hsp90 family is normally comprised of four isoforms that are located in various cellular compartments. Two Hsp90 (the stress-inducible form Hsp90a/HSPC2 and the constitutive form Hsp90 $3 / \mathrm{HSPC} 3$ ) isoforms are located in the cytosol and in the nucleus (20-22); GRP94/HSPC4 is present in the endoplasmic reticulum (ER) $(20,21,23)$ and TRAP1/HSPC5 is found in the mitochondrial matrix (24). Some intracellular Hsp90 isoforms are exported and function in the extracellular environment to regulate the immune response, cell migration and invasion (25-28).

Structurally, Hsp90 is a flexible dimeric protein with each monomer containing three domains: an Nterminal nucleotide-binding domain (NBD); a middle client protein-binding domain (MD); and a Cterminal dimerization domain (DD) (29-31). To perform its molecular chaperone function, Hsp90 is dependent on ATP hydrolysis, and a battery of accessory proteins termed co-chaperones, which assist in the recruitment of client proteins and the regulation of the Hsp90 reaction cycle $(32,33)$. The cytosolic 
Hsp90 isoforms contain a conserved C-terminal MEEVD motif which acts as a docking site for interaction with co-chaperones that possess the tetratricopeptide repeat- (TPR) domain $(34,35)$. Other Hsp90 co-chaperones interact with the molecular chaperone through its NBD or M domain (33). So far, more than 30 co-chaperones have been identified in the mammalian Hsp90 chaperone system. However, the composition of the Hsp90 chaperone system appears to vary across organisms indicating that the function of some co-chaperones may be restricted to specific subsets of client proteins, be required for client protein activation in a species-dependent manner, or be redundant with other co-chaperones (36). Hsp90 is also subject to post-translational modifications, including s-nitroslyation, phosphorylation and acetylation, which may influence its activity, cellular localization or its interaction with co-chaperones, nucleotides or client proteins (37-40). Some Hsp90 isoforms are essential for viability, and maintenance of client proteins that are dependent on the chaperone (41), making it an attractive drug target for diseases including infectious diseases. Several Hsp90 inhibitors, which have been well studied in the laboratory and clinic for antitumor indications $(42,43)$, were also shown to arrest the growth of several kinetoplastids in vitro and have activity against Trypanosoma evansi and T. brucei in mice (44-47). Thus, the repurposing of Hsp90 inhibitors designed for cancer treatment is one strategy to evaluate new and effective anti-trypanosomal agents (48).

Post-genomic analysis of the molecular chaperone complements in kinetoplastid parasites have revealed unprecedented expansion and diversification, highlighting the importance of these protein families in the biology of these organisms (8,9,49-51). In Trypanosoma and Leishmania, the Hsp90 (Hsp83) machinery has a pivotal role in environmental sensing and life cycle control $(44,52,53)$. Several reviews and updated in silico analyses of the Hsp90/HSPC family and Hsp90 heterocomplexes in the annotated genome sequences of intracellular kinetoplastid parasites have been conducted $(8,50,51,54,55)$. However, this has not been the case for the extracellular parasite, T. brucei.

T. brucei exhibits a digenetic lifestyle, and therefore must adapt to fluctuating environmental conditions, such as change in temperature, $\mathrm{pH}$, nutrients and the pressure from the immune system, as it transitions from the gut of the tsetse fly to the body fluids of its mammalian host $(54,56)$. A distinct molecular trait of trypanosomes is their dependence on polycistronic transcription akin to prokaryotes. Trypanosomal mRNAs are mainly generated through trans-splicing and there is a dependence on post-transcriptional mechanisms for gene regulation (57). However, correlation studies comparing the previously reported RNA-seq data of transcript abundance and proteomic data from the procyclic form (PF) and bloodstream form (BSF) of the parasite show that the differences observed between the PF and BSF are two-fold greater at the proteomic level when compared to the transcriptomic level $(58,59)$. Given the complexities of transcription, its incomplete representation of the life cycle stages of the parasite as well 
as its lack of control, trypanosome research has largely shifted to rely on proteomic data (60). Numerous proteomic studies have been conducted in the parasite which have compared protein expression at the different life cycle stages $(58,59,61)$, in the mitochondrion (62), mitochondrial importome (63), respiratome (64), mitochondrial membranes (outer, intermembrane space, inner and matrix) (65), nucleus (60), nuclear pore (66), glycosomes $(67,68)$, flagellum $(69,70)$ and cell surface $(71)$.

T. brucei and the related kinetoplastids rely on post-translational modifications (PTMs) to increase their proteome diversity and complexity (72). Advanced studies in trypanosomes phosphoproteome and acetylome (73-76) indicates phosphorylation and acetylation as the most predominant modifications in T. brucei proteins. Both PTMs are well known for impacting Hsp90 intracellular localization as well as their ability to bind co-chaperones, nucleotides, clients $(72,74)$ and even inhibitors $(77)$. However, the PTMs regulatory dynamic in the organellar TRAP-1 and GRP94 are yet to be elucidated for a global understanding of this critical chaperone activity regulator system.

This paper aimed to provide a comprehensive depiction of the T. brucei Hsp90 chaperone system based on structural, functional, and evolutionary analyses. In silico tools were used to evaluate the domain conservation, predicted subcellular localisations, syntenic and phylogenetic analysis of the Hsp90 chaperone system in T. brucei with respect to both T. b. brucei and T. b. gambiense. The Hsp90 chaperone system was also comparatively analysed in relation to those found in selected kinetoplastid parasites and Homo sapiens. The proteomic findings on Hsp90 and its co-chaperones from the numerous published proteomic data on T. brucei are presented, and we provide updated insights on the adaptability of the parasite from its stage-specific expressed proteins and overall provide a context for identifying new and potential drug targets for HAT.

\section{Materials and Methods}

\section{Database mining, sequence analyses and the determination of the kinetoplastid and human orthologues.}

A BLASTP search using the amino acid sequences of Hsp90 isoforms from the T. b. brucei obtained from previous in silico study (49), and the human HSPC2, HSP90AB1/HSPC3, HSP90B1/HSPC4 and HSPC5 isoforms were used as queries on the TriTrypDB (version 46) database (https://tritrypdb.org/tritrypdb/) (78) and were analyzed in order to determine the Hsp90 complement 
encoded on the T. b. gambiense genome, as well as identify new T. b. brucei Hsp90/HSPC protein members. The e-value was set at a stringent level of $\mathrm{e}^{-10}$ to identify potential Hsp90/HSPC-related sequences for further analysis. Additionally, a keyword search was performed to scan the genome of $T$. b. gambiense for Hsp90/HSPC genes on the TriTrypDB using the search terms: "Hsp90", "Hsp83", "heat shock protein" and "molecular chaperone". The retrieved amino acid sequences from the various keyword searches were screened using SMART 7 (Simple Modular Architecture Research Tool; http://smart.embl-heidelberg.de/) (79) and PROSITE (http://prosite.expasy.org/) (80) for domains annotated by the online servers as "Hsp90".

For identification of T. brucei orthologs of selected cytosolic Hsp90 co-chaperones, the protein sequences of the human co-chaperones were used as queries in a BLASTP search on the TriTrypDB. Reciprocal BLASTP was conducted to determine if the identified putative T. brucei co-chaperone had the closest match to the desired human co-chaperone. The putative amino acid sequences of the cochaperones from both $T$. brucei subspecies were used as queries in a BLASTP search on the National Centre for Biotechnology Information (NCBI) website (www.ncbi.nlm.nih.gov), using the default parameters. If the most similar orthologue in the T. brucei subspecies was identical to the Hsp90 cochaperone sequence used as first query, the sequence of the second query was selected as an orthologue. Reciprocal BLASTP was also conducted for the identification of human and selected kinetoplastid orthologues of the putative Hsp90/HSPC proteins from both T. brucei subspecies.

\section{Phylogenetic and conserved syntenic analysis.}

A phylogenetic tree was constructed to analyse the phylogenetic relationship of the Hsp90/HSPC complements in both T. brucei subspecies. The full-length amino acid sequences for the Hsp90/HSPC family in the selected kinetoplastid parasites were obtained from TriTryDB (78), and the human protein sequences were obtained from the NCBI website (www.ncbi.nlm.nih.gov). Partial amino acid sequences were omitted from the analysis. Gene ID numbers for the Hsp90/HSPC sequences used in this study are provided in Table 1. Multiple sequence alignments were performed using the inbuilt ClustalW program (81) with default parameters in MEGA-X (82), and is provided in the supplementary data, Fig S1. Maximum likelihood (ML) was utilized to find the best model of evolution and was selected by the Bayesian Information Criterion (BIC) implemented in MEGA-X. The amino acid-based Hsp90/HSPC ML phylogeny was reconstructed using the JTT (Jones-Taylor-Thornton) model matrix (83) with gamma distribution shape parameter $(G)$. The ML phylogenetic tree was constructed using MEGA-X (82). The accuracy of the reconstructed tree was assessed using a bootstrap test using 1000 replicates with a pairwise gap deletion mode. The phylogenetic tree for the Hsp90s was unrooted. 
Syntenic analysis was conducted to evaluate the conservation of the gene arrangement of the cytosolic Hsp83 genes in T. brucei and selected kinetoplastid parasites. The conserved syntenic regions surrounding the selected Hsp83 genes were searched by examining the conserved colocalization of neighbouring genes on a scaffold of the T. brucei subspecies (T. b. brucei and T. b gambiense) and selected kinetoplastid parasites for this study using genome information from TriTryDB. The identities of unknown neighbour genes of the selected Hsp83 genes were conducted using a BLASTP search on the NCBI database.

\section{Physiochemical properties, protein expression, and the determination of the organelle distribution for the T. brucei Hsp90/HSPC complement.}

The physiochemical properties, molecular weight $(\mathrm{Da})$ and isoelectric point $(\mathrm{pI})$ of each gene was determined using the compute $\mathrm{pI} / \mathrm{Mw}$ tool from ExPASy (https://web.expasy.org/compute pi/) (84). Data on the previously reported phenotypic RNAi knockdown screen, (85), for each member of the Hsp90/HSPC complement and identified Hsp83 co-chaperones were retrieved from TrypsNetDB (http://trypsnetdb.org/QueryPage.aspx) (86). The predicted organelle distribution for each protein was searched using the TrypTag microscopy project's online server, (87). This project aims at tagging every trypanosome protein with mNeonGreen (mNG) (88) to determine the protein's localization in the cell within the parasite (http://tryptag.org/)(87). Proteomic data from the mitochondrion (62), mitochondrial importome (63), respiratome (65), mitochondrial membranes (outer, intermembrane space, inner and matrix) (65), nucleus (60), nuclear pore (66), glycosomes $(67,68)$, flagellum $(69,70)$ and cell surface (71) were also used for the prediction of the organelle distribution for the T. brucei Hsp90 complements and Hsp90/ HSPC complements and Hsp83 co-chaperones.

\section{Identification of potential post-translational modification sites for the $T$. brucei Hsp83 proteins.}

Mass spectrometric information from a collection of relevant databases on T. brucei PTMs (73,75-77) for the relevant proteins was retrieved using the previously identified accession numbers. Information on the respective PTMs (modification sites, modification types and modified residue) were obtained and the modified residues were mapped onto Fig S1 for all Hsp90 isoforms from T. brucei subspecies (T. b. brucei and T. b gambiense) with orthologues from other kinetoplastids and from human, then analysed for determination of conserved and specific PTMs among the T. brucei Hsp90 complements. 


\section{Results and discussion}

Determination of the $T$. b. brucei and T. b. gambiense Hsp90/HSPC complement.

The protozoan parasite, T. brucei is comprised of three subspecies, with the genomes of T. b. gambiense and T. b. brucei already sequenced $(89,90)$. Any information obtained from the genome of the nonhuman infective T. brucei subspecies, T. b. brucei, can be inferred for the human infective subspecies, T. b. rhodesiense, as the T. b. brucei TREU927 strain displays the full range of known T. brucei phenotypes and possesses similar biological and genetic characteristics (90). However, the T. $b$. gambiense genome was sequenced due to the subspecies displaying profoundly different biological and genetic characteristics (89). An in silico analysis of the Hsp90/HSPC complement in both T. brucei subspecies was conducted to provide an overview of the T. brucei Hsp90 family. The nomenclature and format to categorize the T. brucei Hsp90 family was adopted from our previous study (9). The orthologue of the cytosolic Hsp90 member in T. brucei is termed Hsp83 (91), and thus will be referred to as Hsp83 in this study. This protein displays variable molecular weight amongst different kinetoplastid protists. However, to underscore whether discussing a protein from T. b. gambiense or T. b. brucei, the abbreviations Tbg and Tbb respectively, were used in this study. The orthologous relationships of the Hsp90 family from T. b. brucei and T. b. gambiense to the selected organisms in this study are presented in Table 1, and a comprehensive domain organisation of the predicted T. brucei Hsp90 proteins is illustrated in Fig 1. 
250 Table 1. The Hsp90/HSPC proteins from Trypanosoma brucei with putative orthologues in T. cruzi, L. major, C. fasciculata, B. saltans and 251 H. sapiens.

\begin{tabular}{|c|c|c|c|c|c|c|c|c|}
\hline & H. sapiens & T. brucei & T. cruzic $^{c}$ & L. major & C. fasciculata & B. saltans & & \\
\hline Name $^{a}$ & Gene ID $^{b}$ & Gene ID ${ }^{b}$ & Gene ID ${ }^{b}$ & Gene ID ${ }^{b}$ & Gene ID $^{b}$ & Gene ID $^{b}$ & Localisation $^{d}$ & Reference \\
\hline $\begin{array}{l}\text { HSP90-alpha/HSPC2 } \\
\text { HSP90-beta/HSPC3 }\end{array}$ & $\begin{array}{l}3324 \\
3326\end{array}$ & $\begin{array}{c}\text { Tb927.10.10890 } \\
\text { Tb927.10.10900 } \\
\text { Tb927.10.10910 } \\
\text { Tb927.10.10920 } \\
\text { Tb927.10.10930 } \\
\text { Tb927.10.10940 } \\
\text { Tb927.10.10950 } \\
\text { Tb927.10.10960 } \\
\text { Tb927.10.10970 } \\
\text { Tb927.10.10980 } \\
\text { Tbg972.10.13260 } \\
\text { Tbg972.10.13270 } \\
\text { Tbg972.10.13280 } \\
\text { Tb11.v5.0543* }\end{array}$ & $\begin{array}{c}\text { TcCLB.507713.30 } \\
\text { C4B63_113g25 } \\
\text { C4B63_113g29 } \\
\text { C4B63_113g30 } \\
\text { C4B63_113g33 } \\
\text { C4B63_84g87 } \\
\text { C4B63_84g88 } \\
\text { C4B63_84g89 } \\
\text { Tc_MARK_3581 }\end{array}$ & $\begin{array}{l}\text { LmjF.33.0312 } \\
\text { LmjF.33.0314 } \\
\text { LmjF.33.0316 } \\
\text { LmjF.33.0318 } \\
\text { LmjF.33.0320 } \\
\text { LmjF.33.0323 } \\
\text { LmjF.33.0326 } \\
\text { LmjF.33.0330 } \\
\text { LmjF.33.0333 } \\
\text { LmjF.33.0336 } \\
\text { LmjF.33.0340 } \\
\text { LmjF.33.0343 } \\
\text { LmjF.33.0346 } \\
\text { LmjF.33.0350 } \\
\text { LmjF.33.0355 } \\
\text { LmjF.33.0360 } \\
\text { LmjF.33.0365 }\end{array}$ & $\begin{array}{l}\text { CFAC1_280011900 } \\
\text { CFAC1_280012000 }\end{array}$ & BSAL_87515 & $\begin{array}{c}\text { CYT } \\
\text { NUC } \\
\text { FLAGELLAR } \\
\text { CELL SURFACE }\end{array}$ & $\begin{array}{l}(58) \\
(61) \\
(70) \\
(71) \\
(87)\end{array}$ \\
\hline
\end{tabular}


GRP94/HSPC4

7184

Tb927.3.3580

Tbg972.3.3850

C4B63 10g439

Tc_MARK_3058

LmjF.29.0760

CFAC1 100018800

BSAL_88715

ER

FLAGELLAR

CELL SURFACE

(58)

MITO

cCLB.504153.310

Tb927.11.2650

C4B63_2g430

Tc_MARK_6238
CFAC1_230028300

BSAL_33145
FLAGELLAR
(61)

(70)

(71)

(62)

(87)

\section{2}

$253{ }^{\text {a }}$ The nomenclature for the Hsp90/HSPC proteins from T. b. brucei, and T. b. gambiense were derived according to Folgueira and Requena (2007).

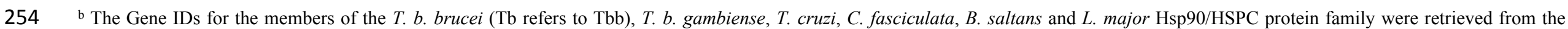

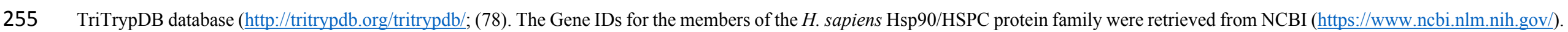

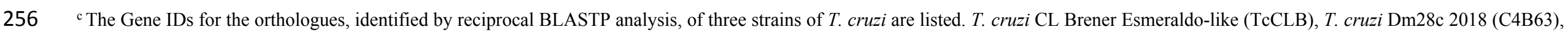
257 and T. cruzi marinkelli strain B7 (Tc_MARK).

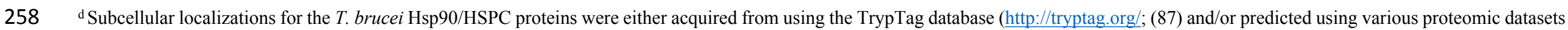
259 and online prediction software listed in the materials and methods.

260 CYT-Cytosol; MITO- Mitochondrion; NUC- Nucleus; ER- Endoplasmic reticulum; GYLCO- glycosomes; FLAGELLAR- Flagellar; CELL SURFACE- Cell surface.

* Putative T. . brucei HSP83 gene has not been assigned to a chromosome on the TriTrypDB database (http://tritrypdb.org/tritrypdb/; (78) yet. 
Fig 1. Schematic representation of the domain architecture of the Hsp90/HSPC proteins in $T$. brucei.

Each protein sequence is represented by a coloured bar with the numbering on the bottom of the bar indicating the length of the protein in amino acid residues. Protein domains and other associated features that were identified using Prosite (80) and SMART (79) are also shown, and include the N-terminal nucleotide binding domain (NBD; red), variable charger linker domain (L; dark blue), middle client protein-binding domain (MD; light blue), a Cterminal dimerization domain (DD; green) and targeting signal peptides (SP; pink). The physiochemical properties, molecular weight (MW) and isoelectric point (pI), for each T. brucei Hsp90 protein was calculated using the compute $\mathrm{pI} / \mathrm{Mw}$ tool from ExPASy (https://web.expasy.org/compute pi/; (84). Data on the phenotypic knockdown screen using RNAi conducted by Alsford et al. (2011), for Hsp90/HSPC protein member is provided: ALL- required for all life cycle stages; BSF- required for bloodstream form; PRO- required for procyclic form; DIFF- required for differentiation; NE- Non-essential; ND-Not determined.

Twelve putative $H s p 90$ genes were identified to be encoded on the T. b. brucei genome (Table 1), which is consistent with previous findings $(49,91)$, while $T$. b. gambiense was identified in this study to only have 5 putative $H s p 90$ genes encoded on its genome. The reduction in the $H s p 90$ gene numbers found in T. b. gambiense could be a consequence of the reduced genome size observed in the human infective subspecies (92). The intraspecific genomic variation is largely associated with tandem or segmental duplications observed in T. b. brucei (89). This study also identified a new unassigned putative Hsp90 gene (Tb11.v5.0543) in the animal infective subspecies, T. b. brucei. Though, whether this gene represents an additional and/or novel Hsp 90 gene needs to be further verified (Table 1). For the putative Hsp90 genes identified in this study for T. b. brucei, 10 of the 12 putative $H s p 90$ genes identified were found to be homologous to Hsp83, whereas in T. b. gambiense, 3 of the 5 putative Hsp90 genes identified were homologous to Hsp83 (Table 1). The remaining two Hsp90 genes found in both T. $b$. brucei (Tb927.3.3580 and Tbg972.3.3850) and T. b. gambiense (Tb927.11.2650 and Tbg972.11.2900) showed significant identity to the ER and mitochondrial resident paralogues of Hsp90, GRP94 and TRAP-1 respectively (Table 1). This indicates that a single gene copy for GRP94 and TRAP-1 is encoded on the genome in both T. brucei subspecies. Phylogenetic analysis shows that the T. brucei Hsp90/HSPC family is also comprised of 3 distinct Hsp90 groups (Hsp83, GRP94 and TRAP-1), which cluster into clades according to protein sequence and subcellular localisation (Fig 2). In contrast to humans with 4 Hsp90 isoforms, there are 3 Hsp90 isoforms (Hsp83, GRP94 and TRAP-1) identified by phylogenetic analysis to be present in all kinetoplastid organisms used in this study (Table 1; Fig 2). 
Fig 2. Phylogenetic analysis of the Hsp90/HSPC family from $T$. brucei in relation to human and selected kinetoplastid parasites.

Multiple sequence alignment of the full-length amino acid sequences of the Hsp90/HSPC gene families in human and selected kinetoplastid parasites. The multiple sequence alignment provided in Fig. S1 was performed using the in-built ClustalW program (81) with default parameters on the MEGA X software (82). The phylogenetic tree was constructed by MEGA X using the Maximum-likelihood method based on the Jones-Taylor-Thornton (JTT) matrix-based model of amino acid substitution (83) with gamma distribution shape parameter (G). The alignment gaps were excluded from the analysis, and the number of amino acid sites used to construct the tree numbered 572. Bootstrap analysis was computed with 1000 replicates. Gene ID/Accession numbers for the T. b. brucei (Tbb), T. b. gambiense (Tbg), T. cruzi (TcCLB, CL Brener Esmeraldo; TcM, marinkellei strain B7; TcD, Dm28c 2018), C. fasciculata (Cf), B. saltans (Bs), L. major (Lmj) and human (Hs; H. sapiens). Hsp90 amino acid sequences can be found in Table S1. The subcellular localisation for Hsp90s is indicated by coloured branches. Red: cytosolic; blue: endoplasmic reticulum; and green: mitochondrion. Scale bar represents 0.2 amino acid substitutions per site.

Previous literature reported that 11 Hsp90 genes are encoded on the Trypanosoma cruzi (T. cruzi) genome (50). In this study we included three different T. cruzi strains: CL Brener Esmeraldo-like (TcCLB), Dm28c 2018 (C4B63), and marinkelli strain B7 (Tc_MARK) to determine the Hsp90/HSPC in the American trypanosome. It was identified in this study that the T. cruzi CL Brener Esmeraldo-like strain encodes 2 Hsp 90 genes, the Dm28c 2018 strain has 9 Hsp 90 genes, and the marinkelli strain B7 has $3 H s p 90$ genes (Table 1). However, it was found in this study that many of the Hsp90 genes homologous to Hsp83 identified in the three T. cruzi strains were partial and/or truncated genes. These genes may be the products of non-sense mutation leading to premature termination of Hsp83, which if expressed in the parasite can code for truncated Hsp83 proteins. These partial and/or truncated Hsp83 genes in this study were omitted from the analysis. The obvious discrepancy in numbers of genes amongst the T. cruzi strains, and its numerous partial and/or truncated Hsp90 sequences calls for reevaluation of its genome annotation. Leishmania major (Lmj) contains the largest Hsp90 family with a total of $19 H s p 90$ genes, 17 of which were found to be homologous to Hsp83, and these findings are like previous studies $(8,49,50)$. Other kinetoplastids included in this study were the non-parasitic Bodo saltans (B. saltans) (93) and the insect infecting Crithidia fasciculata (C. fasciculata) (94), which were found to encode 3, and 4 putative $H s p 90$ genes respectively (Table 1). Both these kinetoplastids were found to possess genes encoding for all three Hsp90 isoforms (Hsp83, TRAP-1 and GRP94), though $C$. fasciculata was identified to possess two Hsp83 gene (Table 1). Early genomic studies suggested that the human genome contained 16 Hsp90/HSPC genes (5 functional and 11 pseudogenes), which have been categorised, according to the proposed standardized guidelines for HSP nomenclature, into 4 
isoforms under the superfamily name HSPC $(12,21)$. In contrast to the kinetoplastid protists, humans have two isoforms of Hsp90 localized in the cytoplasm: the inducible form Hsp90 $/ \mathrm{HSPC} 2$ and the constitutive form HSP90ß/HSPC3 (20). T. brucei Hsp83 is $62 \%$ and $63 \%$ identical at the amino acid level to HsHSPC2 and HsHSPC3 respectively, and this sequence identity increases to over $70 \%$ in the NBD (Fig S1). Phylogenetic analysis has suggested that the two cytosolic isoforms (heat-induced Hsp90 $\alpha$ /HSPC2/HSP90AA2 and constitutively expressed Hsp90ß/HSPC3/HSP90AB1) arose from gene duplication, and the organelle Hsp90s (GRP94/HSPC4 and TRAP-1/HSPC5) developed from a common ancestor (95-97). Hsp83 (Tb927.10.10980) and TRAP-1 (Tb927.11.2650) were identified as phosphoproteins in this study, while kinases are yet to be identified in the ER and little is known about the effect of post-translational modifications on GRP94 $(23,98)$.

\section{Hsp83}

Hsp83 and has been found to be an essential and highly abundant protein, that is encoded by multiple gene copies organized in a head-to-tail tandem array (49). It has been identified in this study and previous studies $(49,91)$ that $T$. b. brucei has been shown to encode for 10 tandem copies of Hsp83 (Fig 3), whereas T. b. gambiense genome encodes 3 tandem copies of Hsp83 (Fig 3). Syntenic analysis revealed that the TbbHsp83 and TbgHsp83 genes are both located on chromosome 10 in a head to tail orientation, with the same genomic organisation being observed in both T. brucei subspecies (Fig 3.). Like T. brucei, a discrepancy in Hsp83 gene copy numbers was also observed for the three T. cruzi strains used in this study (Fig 3). Syntenic analysis revealed that the T. cruzi Dm28c 2018 (C4B63) strain has 16 tandem copies of Hsp83, though 9 were partial sequences (Fig 3), whereas both the CL Brener Esmeraldo-like (TcCLB) and marinkelli strain B7 (Tc_MARK) encode for 2 Hsp 83 genes, with 1 partial gene each (Fig 3). The genomes of the three T. cruzi strains need to be further investigated to determine if the partial sequences of the $H s p 83$ genes are due to sequencing errors or a result of nonsense mutation. L. major has the highest Hsp83 gene copy number with 17 tandem copies (Table 1; Fig 3), correlating with the high abundance of the protein being observed in L. major and several other Leishmania spp. (99). Syntenic regions surrounding the $H s p 83$ genes were found to be virtually conserved across the selected kinetoplastids, with B. saltans being the exception (Fig 3). Thus, the discrepancy in gene copy number of Hsp83 in the two T. brucei subspecies and amongst the kinetoplastid organisms may have arisen from the differences in the life cycle of the kinetoplastids. Datamining of proteomic data revealed that all identified TbbHsp83 (TbbHsp83-1) proteins are present in both life cycle stages of the parasite: the bloodstream stage (BSF) and procyclic stage (PF) $(58,61)$. Though, the protein expression of the TbbHsp83 proteins were reported to be up regulated during at the BSF stage (58), despite gene regulation being unchanged in both the bloodstream and procyclic life 

made available under aCC-BY 4.0 International license. TbbHsp83-10 (Tb927.10.10980) was found in the flagellar proteome (71). 
372 Fig 3. Syntenic analysis of the gene arrangement of the Hsp83 genes in T. brucei and selected kinetoplastid parasites.

The conserved syntenic regions surrounding the selected Hsp83 genes were searched by examining the conserved co-localization of neighbouring genes on a scaffold of the T. brucei subspecies (T. b. brucei and T. b. gambiense) and selected kinetoplastid parasites : T. cruzi CL Brener Esmeraldo-like (TcCLB), T. cruzi Dm28c 2018 (TcD) strain, T. cruzi marinkelli strain B7 (TcM), L. major (Lmj), B. saltans (Bsal) and C. fasciculata (Cfac). The genome information used for this study was acquired from TriTrypDB database (http://tritrypdb.org/tritrypdb/; (78). The identities of unknown neighbour genes of the selected Hsp83 genes were conducted using a BLASTP search on the NCBI database. Abbreviations: ABCF1: ATP-binding cassette sub-family F member 1; WD40: WD40-repeat protein.

The amplification of HSP genes in protozoan parasites has been reported previously $(8,9,51,100)$, and is considered a means by which the parasites increase chaperone levels in order to maintain proteostasis under normal and stressful conditions (53). The heat shock response is a highly conserved transcriptional program that in most organisms involves increased heat-shock gene transcription (101). However, in kinetoplastids, control of gene expression occurs almost exclusively at the posttranscriptional level, and that HSP synthesis during heat shock depends on regulation of mRNA turnover and translational control $(102,103)$. In T. brucei, post-transcriptional regulation of chaperone mRNAs is facilitated by a zinc finger protein, ZC3H11(104). The mRNA transcript levels of TbbHsp83 in BSF parasites increases $>2$-fold after heat shock (105), and is stabilized by ZC3H11 to promote the survival of the parasite (104). Treatment of T. b. brucei BSF parasites with 17-AAG sensitized the parasites to heat shock, as well as caused severe morphological abnormalities and cell cycle disruption (46). Pharmacological inhibition of Hsp83 activity in several Leishmania spp. Induced morphological and biochemical promastigote-to-amastigote differentiation $(53,106,107)$, which mimics environmental triggers such as heat shock and acidic milieu, indicating a pivotal role for Hsp83 in kinetoplastid protists in environmental sensing and life cycle control. Interestingly, treatment of $T$. cruzi bloodstream trypomastigotes with geldanamycin induced morphological changes in the parasites but not life cycle progression (44). Therefore, Hsp90 cellular homeostasis as a key factor for the control of stage differentiation appears to be dependent on the tropism of the parasite and the different regulatory pathways for life cycle control. It would be interesting to investigate if the pharmacological inhibition of Hsp83 effects cellular differentiation amongst the three T. brucei subspecies. and sequence in the kinetoplastid Hsp83 homologues (Fig 2). The 704 amino acid sequences of the 
corresponding TbbHsp83 and TbgHsp83 proteins were found to be almost identical (Fig S1) and contain the predicted canonical domain architecture of typical cytosolic Hsp90s (Fig 1). Despite the overall structural conservation, kinetoplastid Hsp83 proteins possess unique biochemical features which separate them from their human counterparts and can be potentially exploited in selective drug discovery studies. Unlike mammalian Hsp90, which binds ATP but has low basal ATPase activity, TbbHsp83 from T. b. brucei shows potent ATPase activity (108). This enhanced ATPase activity has also been shown in Hsp83 orthologue in T. cruzi (109). As a consequence of its greater affinity for ATP, TbbHsp83 also possesses a greater affinity for Hsp90 NBD specific inhibitors, and thus is more sensitive to inhibition by these compounds than its human orthologues $(46,108)$. In a study conducted by Pizarro and colleagues (2013), biophysical and biochemical techniques were able to identify three short divergent regions in the TbbHsp83 NBD, that they targeted for selective pharmacological inhibition of TbbHsp83 over human Hsp90. The higher ATPase activity is predicted to be a result of the parasites enhanced requirement for proteostasis maintenance by molecular chaperone through stabilizing key cell regulators under hostile conditions (108). This observation is consistent with human Hsp90's pivotal role in some forms of cancer through conformational regulation of labile kinases and ligases $(19,41,43,110)$.

It was also interesting to note that the variable charged linker domain which links the NBD to the MD in cytosolic Hsp90s found in higher eukaryotes is also present in T. brucei (Fig 1). This region is highly divergent in both length and amino acid sequence among Hsp90 proteins of different species and does affect Hsp90 function, co-chaperone interaction, and conformation (111-113). Hsp90 from protozoa often have extended linkers with the malaria parasite, Plasmodium falciparum, exhibiting one of the longest linkers reported thus far (45). Complementation of human and yeast charged linkers by the $P$. falciparum version reduces ATPase activity and affects client protein binding (113), thus indicating that this linker could provide specificity to the activity of Hsp90 from different species. Therefore, comparative analysis of T. brucei Hsp83 proteins with their human counterparts, as well as linker swapping experiments, will be especially useful in understanding the role of the linker region in $T$. brucei Hsp90 biology, and possible future exploitation as a unique drug binding region.

Post-translational modifications, and particularly phosphorylation of tyrosine, serine, and threonine residues at multiple sites of cytosolic Hsp90 is a well-known chaperone activity modulator mechanism in many organisms (114-117). Hsp90 steady-state phosphorylation is species-specific relative to the different cellular environments (116). S53 and S286 were determined to be phospho-modified residues that were conserved within the ten cytosolic T. brucei Hsp83 proteins, while T211, T216, S597 and S694 were conserved in all analysed kinetoplastids in this study (Fig. S1). S374 was conserved in both 
kinetoplastids and humans (Fig. S1). The same phospho-modified residues were previously described for the cytosolic Hsp83 orthologue from L. donovani (117). The following acetylation sites were predicted for TbHsp83: K44, K227, K277, K259, K289, K337, K394, K418, K421, K474, K487, K515 and K533. The residues conserved amongst the other isoforms were mapped in Fig. S1. The predicted N-glycosylation sites, N90, N372 and N612 were conserved in all kinetoplastids and humans, whilst N51 was determined to be specific to T. brucei Hsp83 (Fig. S1). Two ubiquitination sites (K394 and K560) were found conserved in all analysed cytosolic Hsp90 isoforms in this study (Fig. S1).

\section{TRAP-1}

The mitochondrial isoform of the Hsp90/HSPC family was first identified in association with the mammalian tumour necrosis factor 1 (TNF-1) protein, hence termed TRAP-1 (118). It was promptly suggested as a member of the $90-\mathrm{kDa}$ molecular chaperone family due to strong homology with other Hsp90 members (118). Since then, TRAP-1/HSPC5 orthologues have been identified in a variety of eukaryotic and prokaryotic organisms. This study identified a single entry for a putative TRAP-1 gene annotated in the genomes of both T. b. brucei (Tb927.11.2650) and T. b. gambiense (Tbg972.11.2900) (Table 1). The selected kinetoplastids in this study also encoded a single copy of TRAP-1 (Table 1) which was consistent with previous studies (49), except for T. cruzi which was previously stated to encode for two TRAP-1 orthologues $(49,50)$. Phylogenetic analysis indicates a general conservation of kinetoplastid TRAP-1 (Fig 2), though little experimental characterization of these genes has been conducted in kinetoplastids. It is predicted that the cellular role of the kinetoplastid TRAP-1 proteins will be orthologous to HsHSPC5, whose major function is to maintain mitochondrial integrity, modulate mitochondrial metabolism and protect against mitochondrial apoptosis (24). Furthermore, HSPC5 counteracts protein aggregation inside the mitochondria and supports protein folding (119), leading to healthy, intact mitochondria.

Mammalian TRAP-1 orthologues are localized predominantly in the mitochondrial matrix, where at least 6 different protein variants were found resulting from differing splicing patterns, amino acid additions and/or deletions $(120,121)$. The translation of the main TRAP-1 mRNA generates a precursor protein of 704 amino acids, that contains a putative 59-amino acid, $\mathrm{N}$-terminal mitochondrial import sequence which is removed upon organelle import $(121,122)$. It was predicted that both TbbTRAP-1 and TbgTRAP-1 localize in the mitochondria, as the proteins possess a positively charged $\mathrm{N}$-terminal leader sequence (Fig 1). Proteomic and localisation studies confirmed that TbbTRAP-1 localises to the mitochondria $(62,87)$, the protein was also detected in the flagella of $T$. b. brucei BSF parasites $(70)$ (Table 1). The subcellular distribution of TbbTRAP1 during the parasite's life cycle could be related to 
the shape and functional plasticity of the T. brucei single mitochondrion, which undergoes profound

477 alterations to adapt to the different host environments (123). Phenotypic knockdown of TbbTRAP-1

478 had a detrimental effect on the survival and fitness of the parasite at the procyclic stage of its life cycle

479 and negatively affected parasite differentiation (85). Thus, T. brucei TRAP-1 proteins may be an

480 important modulator of mitochondrial bioenergetics at the procyclic stage, as well play an integral role

481 in parasite pathogenesis.

In terms of PTMs, 3 putative phosphorylation sites were found in the middle domain of TRAP-1. S286 and S363 were specific phosphorylation sites for TRAP-1 and S374 was conserved amongst all the Hsp90 proteins (Fig. S1). Several amino acids have been reported as potential targets for posttranslational modifications in human TRAP-1, yet its phosphorylation mechanism remains to be revealed (24). K109, K480 and K601 were predicted to be specific acetylation sites for TbTRAP-1. Additional TbTRAP-1 putative acetylation sites on lysine residues were conserved amongst the mitochondrial isoforms from all analysed taxon (Fig. S1). Most of these PTMs of Hsp90 and other inferences stated here are yet to be verified experimentally

491

\section{GRP94}

The glucose-regulated $94 \mathrm{kDa}$ protein (GRP94) is a Hsp90 family member residing in the lumen of the endoplasmic reticulum (ER) (98), where it is involved in the maturation of membrane-resident and secreted protein clients (23). GRP94 is present as a single gene in all metazoa, although the gene is not found in many unicellular organisms such as bacteria, archaea, yeast, and most fungi (23). This study identified a single putative entry for the GRP94 gene in both T. brucei subspecies and the selected kinetoplastid protists (Table 1). These findings are consistent with previous findings for T. brucei and L. major (49), though previous reports indicated that T. cruzi CL Brener Esmeraldo-like strain encodes determine if these partial sequences of the GRP94 genes (TcCLB.506591.4 and TcCLB.503811.10) are due to sequencing errors.

504

Both TbbGRP94 and TbgGRP94 genes are present on chromosome III and encode proteins considerably longer in amino acid sequence when compared to Hsp83 (Fig 1), which is characteristic of GRP94 protein members $(13,124)$. GRP94 proteins share structural similarity with cytosolic Hsp90 proteins, though the N-terminus contains an ER signal peptide while the C-terminal MEEVD peptide 
TbbGRP94 and TbgGRP94 indicates that the GRP94 proteins share domain architecture with typical

511 GRP94 proteins including the possession of an N-terminal ER signal peptide (Fig 1). However, a

512 variation in the C-terminal ER retention motif, KDEL, is observed in all the kinetoplastid orthologues

513 of GRP94; AGDL in Trypanosoma spp., KEEL in B. saltans, EGDL in C. fasciculata and all

514 Leishmania spp (Fig S1). Phylogenetic analysis indicates that the GRP94 proteins in kinetoplastid

515 protists could have evolved separately from their mammalian orthologues (Fig 2), perhaps to fulfil a

516 specific role within the parasites. Proteomic studies confirm the presence of GRP94 in flagella and cell

517 surface $(70,71)$.

519 In kinetoplastids, the first recognized and characterized GRP94 gene was in Leishmania infantum ( $L$.

520 infantum). The GRP94 orthologue in Leishmania infantum (L. infantum) was shown to localise in the

521 ER and shares many of the activities of GRP94s of other eukaryotes (125). Unlike GRP94 in

522 mammalian cells, LinGRP94 is not essential for cell viability and LinGRP94 mRNA is induced

523 developmentally rather than by canonical GRP94-inducing stresses (125). The protein was highly

524 immunogenic during Leishmania infection (126,127), and essential for lipophosphoglycan (LPG)

525 assembly (125), an abundant surface glycolipid of Leishmania promastigotes that is critical to parasite

526 virulence (128). Effectively, the critical role of GRP94 in Leishmania appears to be adapted to the

527 synthesis of glycoconjugates and directing the host immune response implicating a pivotal role in

528 parasite virulence (125). However, whether this specialized role is conserved in T. brucei and other

529 kinetoplastid parasites will need to be elucidated. The function and cellular roles of TbGRP94 should

530 be explored, given the immunogenic and antigenic properties shown by the L. infantum GRP94, as this

531 protein could constitute a valuable molecule for diagnostic purposes, and quite possibly a potential

532 candidate for studies of protective immunogenicity.

\section{The T. brucei Hsp83 co-chaperone system}

536

537 In all organisms, Hsp90 is a dynamic protein that undergoes a conformational cycle whose directionality

538 is determined in large part by ATP binding and hydrolysis, together with a cohort of co-chaperones

$539(35,129,130)$. The Hsp90 chaperone ensembl can vary in composition depending on the client proteins,

540 but usually includes Hsp70/J-protein, p23, immunophilins, Aha1 and STIP1 (HOP) (130). The variation

541 in subunit composition across organisms appears to be related to the fact that the function of some

542 Hsp90 co-chaperones may be restricted to specific subsets of client proteins, be required for client

543 protein activation in a species-dependent manner, or made redundant by other co-chaperones (36). The 
544 Hsp90 chaperone system in intracellular protozoan parasites has been explored in previous studies 545 (55,131). Thus, using the human and kinetoplastid systems, this study analysed the composition of the

546 T. brucei Hsp83 chaperone system. It was determined in this study that T. brucei possesses an almost 547 complete set of co-chaperones (Table 2), with the only notable absence being cell division cycle 37 548 (Cdc37). The absence of a gene encoding for Cdc37 has also been noted in several intracellular 549 protozoan parasites $(55,117,132,133)$ and was not evident in $10 / 19$ species examined by a study 550 conducted by Johnson and Brown (2009). Cdc37 is a co-chaperone that has a specialized and 551 indispensable role in the maturation and/or stabilization of a large subset of protein kinases (134). The 552 absence of $\mathrm{Cdc} 37$ in some species shows that clients that are dependent on a specific cochaperone in 553 one species may not require Hsp90 for function in other species, thus the protein kinases in protozoan 554 parasites may have evolved in such a way that the proteins bind a different co-chaperone or are 555 independent of Hsp90 for function. Since little is known about why a protein becomes dependent on 556 Hsp90 for activity or stability, it poses interesting questions on the mechanism by which the maturation 557 and regulation of protein kinases in protozoan parasite is mediated dependent or independent of Hsp83. 558 Exploration of this mechanism may provide a potential avenue for chemotherapeutics since protein 559 kinases are also an attractive drug target in infectious disease, such as African Trypanosomiasis. The 560 Hsp70/J-protein machinery from T. brucei have been explored previously (9). The identified Hsp83 co561 chaperones in both T. brucei subspecies are listed in Table 2, and a comprehensive domain organisation 562 of these predicted proteins is illustrated in Fig 4. Additionally, the Hsp83 co-chaperones were 563 categorised in this study based on the presence of the TPR domain. 
H. sapiens.

\begin{tabular}{cccccccc}
\hline & H. sapiens & T. brucei & T. cruzic & L. major & C. fasciculata & B. saltans \\
\hline Name & Gene ID & & Gene ID & Gene ID & & Gene ID & \\
\hline
\end{tabular}

A: TPR-containing Hsp83 co-chaperones

\begin{tabular}{|c|c|c|c|c|c|c|c|c|}
\hline STi1/HOP & 10963 & $\begin{array}{c}\text { Tb927.5.2940 } \\
\text { Tbg972.5.4130 }\end{array}$ & $\begin{array}{l}\text { Tc_MARK_9009 } \\
\text { C4B63_59g115 }\end{array}$ & LmjF08.1110 & CFAC1_020023900 & BSAL_57725 & $\begin{array}{c}\text { CYTO } \\
\text { NUC } \\
\text { CELL } \\
\text { SURFACE } \\
\text { (BSF, PF) }\end{array}$ & $\begin{array}{l}(59) \\
(58) \\
(61) \\
(71) \\
(87)\end{array}$ \\
\hline PP5 & 5536 & $\begin{array}{c}\text { Tb927.10.13670 } \\
\text { Tbg972.10.16800 }\end{array}$ & $\begin{array}{l}\text { TcCLB.507993.190 } \\
\text { C4B63_4g368 }\end{array}$ & LmjF.18.0150 & CFAC1_140007400 & BSAL_15705 & $\begin{array}{c}\text { CYTO } \\
\text { (BSF, PF) }\end{array}$ & $\begin{array}{l}(59) \\
(58) \\
(61) \\
(87)\end{array}$ \\
\hline Cyp40 & 5481 & $\begin{array}{c}\text { Tb927.9.9780 } \\
\text { Tbg972.9.5630 }\end{array}$ & $\begin{array}{c}\text { TcCLB.506885.400 } \\
\text { Tc_MARK_4311 } \\
\text { C4B63_2g294 }\end{array}$ & LmjF.35.4770 & CFAC1_300099000 & BSAL_06490 & $\begin{array}{c}\text { CYTO } \\
\text { FLAGELLAR } \\
\text { (BSF) }\end{array}$ & $\begin{array}{c}(135) \\
(87)\end{array}$ \\
\hline DnaJC7/Tpr2 & 7266 & $\begin{array}{l}\text { Tb927.10.4900 } \\
\text { Tbg972.10.5950 }\end{array}$ & $\begin{array}{c}\text { TcCLB.504203.60 } \\
\text { Tc_MARK_8493 } \\
\text { C4B63_13g112 }\end{array}$ & LmjF.36.0500 & CFAC1_250012000 & BSAL_30720 & $\begin{array}{c}\text { CYTO } \\
\text { NUC } \\
\text { (BSF, PF) }\end{array}$ & $\begin{array}{l}(58) \\
(59) \\
(87)\end{array}$ \\
\hline
\end{tabular}




\begin{tabular}{|c|c|c|c|c|c|c|c|c|}
\hline KBP5 & 2289 & $\begin{array}{c}\text { Tb927.10.16100 } \\
\text { Tbg972.10.19710 }\end{array}$ & $\begin{array}{c}\text { TcCLB.511353.10 } \\
\text { Tc_MARK_4665 } \\
\text { C4B63_157g28 } \\
\text { C4B63_171g30 }\end{array}$ & LmjF.19.1530 & CFAC1_210025000 & $\begin{array}{l}\text { BSAL_03610 } \\
\text { BSAL_65235 }\end{array}$ & $\begin{array}{c}\text { CYTO } \\
\text { FLAGELLAR } \\
\text { (BSF, PF) }\end{array}$ & $\begin{array}{l}(59) \\
(58) \\
(61) \\
(70) \\
(87)\end{array}$ \\
\hline SGT & 6449 & $\begin{array}{c}\text { Tb927.6.4000 } \\
\text { Tbg972.6.3780 }\end{array}$ & $\begin{array}{l}\text { TcCLB.511737.10 } \\
\text { Tc_MARK_2022 } \\
\text { C4B63_18g260 }\end{array}$ & LmjF.30.2740 & CFAC1_260051600 & BSAL_66445 & $\begin{array}{c}\text { CYTO } \\
\text { FLAGELLAR } \\
\text { CELL } \\
\text { SURFACE } \\
\text { (BSF, PF) }\end{array}$ & $\begin{array}{l}(58) \\
(61) \\
(59) \\
(70) \\
(71) \\
(87)\end{array}$ \\
\hline p23 & 10728 & $\begin{array}{c}\text { Tb927.9.10230 } \\
\text { Tb927.10.2620 } \\
\text { Tbg972.9.5930 } \\
\text { Tbg972.10.3260 }\end{array}$ & $\begin{array}{c}\text { TcCLB.509551.70 } \\
\text { TcCLB.506407.60 } \\
\text { C4B63_2g235 } \\
\text { C4B63_47g40 }\end{array}$ & $\begin{array}{l}\text { LmjF.35.4470 } \\
\text { LmjF.34.0210 }\end{array}$ & $\begin{array}{l}\text { CFAC1_300096200 } \\
\text { CFAC1_290030000 }\end{array}$ & BSAL_38665 & $\begin{array}{c}\text { CYTO } \\
\text { FLAGELLAR } \\
\text { NUC }\end{array}$ & (87) \\
\hline Aha1 & 10598 & $\begin{array}{c}\text { Tb927.10.13710 } \\
\text { Tbg972.10.16840 }\end{array}$ & $\begin{array}{l}\text { TcCLB.507993.150 } \\
\text { Tc_MARK_4860 } \\
\text { C4B63_4g357 }\end{array}$ & LmjF.18.0210 & CFAC1_140008400 & BSAL_15670 & $\begin{array}{c}\text { CYTO } \\
\text { NUC } \\
\text { (BSF, PF) }\end{array}$ & $\begin{array}{l}(59) \\
(58) \\
(61) \\
(87)\end{array}$ \\
\hline
\end{tabular}

$572{ }^{b}$ The Gene IDs for the orthologues, identified by reciprocal BLASTP analysis, of three strains of T. cruzi are listed. T. cruzi CL Brener Esmeraldo-like (TcCLB), T. cruzi Dm28c 2018 (C4B63), 573 and T. cruzi marinkelli strain B7 (Tc_MARK). 
${ }^{c}$ Subcellular localizations for the T. brucei Hsp83/HSPC co-chaperone proteins were acquired from using the TrypTag database (http://tryptag.org/; (87) and/or determined using various proteomic datasets listed in the materials and methods.

CYT-Cytosol; MITO- Mitochondrion; NUC- Nucleus; ER- Endoplasmic reticulum; GYLCO- glycosomes; FLAGELLAR- Flagellar; CELL SURFACE- Cell surface.

23 | $P$ a g e 
581 Fig 4. Schematic representation of the domain architecture of the Hsp83 TPR and nonTPR co-chaperones in $T$. brucei.

583 Each protein sequence is represented by an open bar with the numbering on the bottom of the bar indicating the length of the protein in amino acid residues. Protein domains and other associated features that were predicted using Prosite (80) and SMART (79) are also shown. The physiochemical properties, molecular weight (MW) and isoelectric point (pI), for each T. brucei Hsp83 co-chaperone was calculated using the compute $\mathrm{pI} / \mathrm{Mw}$ tool from ExPASy (https://web.expasy.org/compute_pi/; (84). Data on the phenotypic knockdown screen, using RNAi conducted by Alsford et al. (2011), for the Hsp83 co-chaperones are provided: ALL- required for all life cycle stages; BSF- required for bloodstream form; NE- Non-essential; ND-Not determined.

Stress-inducible protein 1 (STI1), also known as Hsp70/Hsp90 organizing protein (HOP or STIP1) in mammals, is one of the best studied co-chaperones in the Hsp90 reaction cycle $(136,137)$ as it acts as an adaptor protein, mediating the interaction between Hsp70 and Hsp90 through its TPR domains (138140). STI1/HOP is a widely conserved Hsp90 co-chaperone and has been annotated and characterized across diverse organisms including several kinetoplastid protists. Initially thought to be an indispensable protein, recent discoveries in yeast and some eukaryotes show that direct interaction can take place in vitro between Hsp70 and Hsp90 in the absence of HOP $(141,142)$. A single STI/HOP gene was found encoded in both T. brucei subspecies (Table 2), with the amino acid sequence indicating canonical STI/HOP domain architecture (Fig 4). Nine TPR motifs arranged into three TPR domains (TPR1, TPR2A and TPR2B) in addition to two domains rich in proline and aspartic acid (DP1 and DP2) were predicted $(143,144)$. Both STi/HOP orthologues in T. cruzi and L. major were found to immunoprecipitate with Hsp83 and Hsp70 as well as co-localize with these chaperones in the cytoplasm and/or around nucleus $(145,146)$. The expression of HOP isoforms was increased in response to different environmental stresses $(145,146)$ with LmjHOP being up regulated when the parasites are exposed to heat stress conditions (145), whereas only nutritional stress induced expression of TcSTi in

611 the late growth phase of epimastigotes (146). The Hsp90-STil complex in L. major and T. cruzi has

612 been shown to be pivotal to parasite differentiation $(107,145)$. Proteomic analysis in Trypanosoma

613 brucei indicates that TbbStil is part of the cell surface (PF) proteome during the procyclic stage (71).

614 Though TbbSti1 is present in both BSF and PF stages of the parasite, it was more highly expressed in 
the bloodstream form $(58,59,61)$. These data suggest that the STil orthologue in both T. brucei subspecies should function as an adaptor protein for TbHsp83 and TbHsp70s, participating in the foldosome apparatus necessary for maintaining proteostasis, cytoprotection and modulating parasite differentiation.

\section{PP5}

Protein phosphatase 5 (PP5) is a member of the PPP family of serine/threonine protein phosphatases and it associates with Hsp90 in complexes during client protein maturation (147-149). PP5 is characteristically unique from other PPP family members in that it possesses an N-terminal TPR domain (150), which mediates interaction with Hsp90 (151). This interaction enables PP5 to modify the phosphorylation status of Hsp90 client proteins (149). The gene for PP5 in T. b. brucei (TbbPP5) has been extensively studied. TbbPP5 encodes a $\sim 52-\mathrm{kDa}$ protein that possesses the canonical N-terminal TPR domain and phosphatase catalytic domain (152) as shown in Fig 4. TbbPP5 interacted with TbbHsp83 in vivo and co-localized with the chaperone in the cytosol of PRO parasites (56). Both TbbPP5 and TbbHsp83, upon heat shock and geldanamycin treatment, accumulated in the nucleus (56), indicating that both TbbPP5 and TbbHsp83 translocate to the nucleus when the parasites are exposed to proteotoxic stresses (56). TbbPP5 was detected in both BSF and PF stages of the parasite but upregulated in the procyclic form $(58,59,61)$. Overexpression of TbbPP5 was found to partially negate the effect of geldanamycin treatment on cell growth, which indicates that the co-chaperone enhances the chaperoning function of TbbHsp83 and promotes the folding and maturation process of important regulatory molecules, which facilitate cell growth.

\section{Peptidyl-prolyl cis-trans isomerases (PPIases)}

The immunophilin superfamily consists of highly conserved proteins with rotamase or peptidylprolyl cis-trans-isomerase (PPIase) activity that accelerates protein folding by mediating the isomerization of X-Pro-peptide bonds $(153,154)$. The best characterized PPIases belong to two families, the cyclophilintype (Cyp) and the FKB-506 drug-binding protein type (FKBP) (155). Data mining of the T. brucei genome identified that Cyp40 and a putative FKB-506 binding like protein (FKBPL) are present in the extracellular parasite proteome (Table 2). Investigation of the domain structure and sequence conservation indicate that both Cyp40 and FKBPL in T. brucei were shown to display the characteristic two-domain structure of a N-terminal PPIase domain and a C-terminal TPR domain (Fig 4). Though it must be noted that the C-terminal TPR domain in kinetoplastid Cyp40 underwent substantial evolutionary modification (156), thus potentially impacting Cyp40-Hsp83 interactions. Future 
650

651

652

653

654

655

656

657

658

659

660

661

662

663

664

665

666

667

668

669

670

671

672

673

674

675

676

677

678

679

680

681

682

683

structure/function studies should explore the effect these modifications have on the isomerase and chaperone activities of the protein in comparison to its human counterpart.

Studies conducted on the Cyp40 orthologue in $L$. donovani have revealed that the protein functions in Leishmania stage-specific morphogenesis, motility, and the development of infectious-stage parasites $(156,157)$. The study conducted by Yau and colleagues (2014) also suggested that LdCyP40 and LdFKBP2 functions in regulating Leishmania cytoskeletal dynamics. Given the capacity of CyP40 and FKBP52 to compete for molecular partners (158), LdCyP40 may interact with microtubules to promote tubulin polymerization as a means of counteracting LdFKBP52-mediated depolymerization. RNAimediated knockdown of both Cyp40 and FKBPL in T. b. brucei parasites demonstrated that these proteins are essential at the BSF stage and parasite differentiation $(58,59,61,85)$. Proteomic data predicted these proteins to reside in the cytosol and flagellar $(70,135)$. Together this data indicates that T. brucei CyP40 and FKBPL may play essential roles in morphogenesis, motility, and the development of infectious-stage parasites.

\section{$\mathbf{J 5 2}$}

The J-protein family is a major subset of co-chaperones for the Hsp70 chaperone machinery and they are broadly classified into four subtypes (I-IV). The J-protein family from T. brucei has been explored previously (9). It was shown in that study that J52 is one of six type III J proteins in $T$ brucei that possesses the TPR domain (others are J42, J51, J52, J53, J65 and J67) (9). J52 is predicted to reside in the cytosol together with J51 and J42 (9). DnaJC7/Tpr2, the human orthologue of J52 was first identified as a cytosolic protein via a two-hybrid screen for interaction with a GAP-related segment (GRD) of neurofibromin. It was reported to encode seven TPR units and possess a domain of high similarity to the DnaJ family (159). Tpr2 also regulates the multichaperone system involving Hsp70 and Hsp90 but in a nucleotide independent manner with Hsp90. DnaJC7 is predominantly thought to be involved in retrograde transport of client proteins from Hsp90 to Hsp70 (160,161). Proteomic analysis in T. brucei showed J52 to be upregulated in the procyclic form of the parasite $(58,59)$.

\section{Small glutamine-rich TPR-containing protein (SGT)}

The small glutamine-rich TPR-containing protein (SGT) is a co-chaperone involved in a specific branch of the global cellular quality control network that determines the fate of secretory and membrane proteins that mislocalize to the cytosol $(162,163)$. Human SGT is a modular protein characterized by 
three characteristic sequence motifs, namely an N-terminal dimerization domain, central TPR domain and a glutamine-rich region at the C terminus (164). The SGT orthologues identified in kinetoplastid protists are atypical (Table 2) as these proteins all lack the characteristic glutamine-rich region and contain a substituted region with charged amino acid residues (165). Proteomic analysis in T. brucei identified TbbSGT to be upregulated in the procyclic form of the parasite as well as part of the flagellar and cell surface proteome $(58,59,61,70,71)$. The SGT orthologue in L. donovani is an essential protein for $L$. donovani promastigote growth and viability (165). LdSGT was shown to form large, stable complexes that included Hsp83, Hsp70, HIP, HOP, J-proteins, and Hsp100 (165), whereas recombinant L. braziliensis SGT was shown to interact with both LbHsp90 and HsHsp70-1A (166). Therefore, the orthologous proteins in $T$. b. brucei and $T$. b. gambiense may have developed the same activity and assist in the formation of the T. brucei Hsp83 chaperone system. Though future studies should be conducted to elucidate SGT-Hsp70/Hsp83 interaction in T. brucei.

\section{Non-TPR containing Hsp83 co-chaperones}

\section{p23}

The co-chaperone p23 is a small acidic protein that binds the Hsp90 NBD to stabilise the closed conformation of Hsp90, inhibiting ATPase activity and prevent client protein release from the complex $(167,168)$. In addition to its HSP90 co-chaperone function, p23 has its own chaperoning activity in vitro and can suppress the aggregation of denatured proteins $(169,170)$. In silico analysis of the genomes of both $T$. brucei subspecies revealed that the parasite possesses two evolutionarily divergent p23 orthologues, and subsequently these orthologous proteins were named p23a and p23b (Table 2). The possession of two putative p23 proteins was found to be conserved in all the selected kinetoplastid protists in this study except $B$. saltans (Table 2). The Tbp23a and Tbp23b proteins share $28 \%$ identity to each other and share $33 \%$ and $26 \%$ identity respectively to human p23. Additionally, RNAi knockdown of these proteins showed that each p23 protein is essential to parasite viability at specific stages of the life cycle (Fig 4). The orthologs of these proteins have been explored in two Leishmania spp. (171). Both proteins in L. braziliensis possessed intrinsic chaperone activity, but they have different client protein specificities; they also inhibit LbrHsp83 ATPase activity to different extents (171). Such functional differences might be important in both Hsp90 regulation and in their interactions with client proteins during the life stage transformations of kinetoplastid parasites. However, to support these assertions, more functional and in vivo studies of kinetoplastid p23a and p23b proteins are needed. 


\section{Aha1}

Aha1 has been identified as the primary activator of the ATPase activity of Hsp90 and it acts independent of the other co-chaperones. Homologues of Aha1 have been identified across species from yeast to mammals. Aha1 binds with both its N- and C-terminal domain (Fig 4) to the NBD and MD of Hsp90 to facilitate the dimerization of the chaperone (172-174). Data mining of the T. brucei genome identified that the parasite encodes for a single Ahal gene (Table 2). The Ahal orthologue in $L$. braziliensis (LbrAha1) has been characterized, where it was shown to be a cognate protein that shared several structural and functional properties with the human and yeast orthologues. This suggested similar functional mechanisms among these proteins despite the low degree of conservation in the amino acid sequence (131). Recombinant LbrAha1 stimulated the weak ATPase activity of recombinant LbrHsp83 by around 10-fold exhibiting a cooperative behaviour according to the model that two LbrAha1 molecules can act on one LbHsp83 dimer (131). Data from proteomic analysis in T. brucei revealed that TbbAha1 is up regulated in the BSF stage of the parasite $(59,61,175)$ as well as being essential to parasite viability at this stage of life cycle (85).

Two other co-chaperones in T. brucei had previously been identified, a TPR domain protein identified as Cns1(Tb927.10.11380) and a component of motile flagella 56 (Tb927.9.10490), orthologue of human Pih1 (130). Little has been done to explore these two proteins. So far, only the cytosolic Hsp90 has been shown to require the function of co-chaperones, the other forms of Hsp90 function in the absence of co-chaperones $(176,177)$.

\section{Conclusion}

The Hsp90 family contains an abundant and essential group of proteins which are highly conserved and implicated in a myriad of cellular functions. Due to their role in cellular proteostasis, they have been implicated in the pathology of many diseases which warrants their targeting as therapeutics (18). Previous studies on the Hsp90 complexes of intracellular kinetoplastids such as Leishmania and T. cruzi have been conducted (50) but not on the extracellular T. brucei. Despite the conservation, distinctive differences exist across species and call for further investigation. In this study we report the in silico study of the Hsp90 family and its chaperone complement in T. brucei. T. b. brucei was found to encode 12 putative Hsp90 proteins, 10 of which are cytosolic (Hsp83). Multiple copies of Hsp83 may allow the parasite to reach a high synthesis level of the proteins in an organism that relies on posttranscriptional regulation and this explains its high levels in the cell even under non-stress conditions $(8,50)$. The expansion of the Hsp90 chaperone complement also reiterates its importance in the biology and functioning of kinetoplastids (49-51). Hsp83 was also found present in both stages of the parasite 
but upregulated in the blood stream form (BSF), this is similar to previous findings of much higher transcripts of Hsp83 in blood stream forms of T. brucei reflecting their temperature induced role of differentiation (52). The upregulation of Hsp83 together with the co-chaperone Stilin the BSF may be a further indication of their heat inducibility and involvement in cell defence just as seen in Hsp70 (51).

Hsp90 has been established to partner with co-chaperones to maintain homeostasis, however, Hsp90 seems to partner with the various co-chaperones as dictated by the client being chaperoned $(178,179)$. This study identified 8 co-chaperones in the T. brucei Hsp83 chaperone system which is less than the number of co-chaperones in the human system, confirming that the Hsp90 chaperone machinery is species specific (130). A detailed report for clients in Hsp90 is still largely absent (54). Previous studies have indicated that inhibitors targeting Hsp83 have been shown to cure mice of $T$. brucei infection, although the toxicity of inhibitors to Hsp90 in higher eukaryotes is attributed to a functional loss of client proteins and possible cell cycle arrest (46). Most of the identified Hsp90 client proteins in mammals are kinases (19). Despite the fact that most clients for T. brucei Hsp90 have not been identified, over 170 protein kinases (about $30 \%$ of the number present in their human host), have been recognised $(75,180)$. In addition to being regulated by co-chaperones, Hsp90 is also regulated by various post-translational modifications. Some of these PTM sites have been indicated as potential regulatory sites which affect the binding affinity of inhibitors in PfHsp90 (45). The T. brucei Hsp90, its co-chaperone network, post-translational modifications, and its regulatory mechanisms as well as the subtle structural differences compared to human Hsp90 all provide a context for a Hsp90-targeted therapy in T. brucei.

\section{References}

1. Brun R, Blum J, Chappuis F, Burri C. Human African trypanosomiasis. The Lancet. 2010 Jan 9;375(9709):148-59.

2. Fèvre EM, Wissmann $B$, Welburn SC, Lutumba P. The Burden of Human African Trypanosomiasis. PLoS Negl Trop Dis. 2008 Dec 23;2(12):e333.

3. Simarro PP, Cecchi G, Paone M, Franco JR, Diarra A, Ruiz JA, et al. The Atlas of human African trypanosomiasis: a contribution to global mapping of neglected tropical diseases. Int J Health Geogr. 2010 Nov 1;9(1):57.

4. Büscher P, Cecchi G, Jamonneau V, Priotto G. Human African trypanosomiasis. The Lancet. 2017 Nov 25;390(10110):2397-409. 
5. Alsan M. The Effect of the TseTse Fly on African Development. Am Econ Rev. 2015 Jan $1 ; 105(1): 382-410$.

6. Morrison LJ, Vezza L, Rowan T, Hope JC. Animal African Trypanosomiasis: Time to Increase Focus on Clinically Relevant Parasite and Host Species. Trends Parasitol. 2016 Aug 1;32(8):599-607.

7. Barrett MP, Croft SL. Management of trypanosomiasis and leishmaniasis. Br Med Bull. 2012 Dec 1;104(1):175-96.

8. Requena JM, Montalvo AM, Fraga J. Molecular Chaperones of Leishmania : Central Players in Many Stress-Related and -Unrelated Physiological Processes. BioMed Res Int. 2015;2015:1-21.

9. Bentley SJ, Jamabo M, Boshoff A. The Hsp70/J-protein machinery of the African trypanosome, Trypanosoma brucei. Cell Stress Chaperones. 2019 Jan 1;24(1):125-48.

10. Zininga T, Shonhai A. Small Molecule Inhibitors Targeting the Heat Shock Protein System of Human Obligate Protozoan Parasites. Int J Mol Sci. 2019 Jan;20(23):5930.

11. Csermely P, Schnaider T, So"ti C, Prohászka Z, Nardai G. The 90-kDa Molecular Chaperone Family: Structure, Function, and Clinical Applications. A Comprehensive Review. Pharmacol Ther. 1998 Aug 1;79(2):129-68.

12. Chen B, Zhong D, Monteiro A. Comparative genomics and evolution of the HSP90 family of genes across all kingdoms of organisms. BMC Genomics. 2006 Jun 17;7:156.

13. Johnson JL. Evolution and function of diverse Hsp90 homologs and cochaperone proteins. Biochim Biophys Acta BBA - Mol Cell Res. 2012 Mar 1;1823(3):607-13.

14. Jakob U, Meyer I, Bügl H, André S, Bardwell JCA, Buchner J. Structural Organization of Procaryotic and Eucaryotic Hsp90. Influence of divalent cations on structure and function. J Biol Chem. 1995 Jun 16;270(24):14412-9.

15. Hartl FU, Bracher A, Hayer-Hartl M. Molecular chaperones in protein folding and proteostasis. Nature. 2011 Jul;475(7356):324-32.

16. Hoter A, El-Sabban ME, Naim HY. The HSP90 Family: Structure, Regulation, Function, and Implications in Health and Disease. Int J Mol Sci. 2018 Aug 29;19(9). 
17. Echeverría PC, Bernthaler A, Dupuis P, Mayer B, Picard D. An Interaction Network Predicted from Public Data as a Discovery Tool: Application to the Hsp90 Molecular Chaperone Machine. PLOS ONE. 2011 Oct 11;6(10):e26044.

18. Samant RS, Clarke PA, Workman P. The expanding proteome of the molecular chaperone HSP90. Cell Cycle. 2012 Apr 1;11(7):1301-8.

19. Taipale M, Krykbaeva I, Koeva M, Kayatekin C, Westover KD, Karras GI, et al. Quantitative Analysis of Hsp90-Client Interactions Reveals Principles of Substrate Recognition. Cell. 2012 Aug 31;150(5):987-1001.

20. Subbarao Sreedhar A, Kalmár É, Csermely P, Shen Y-F. Hsp90 isoforms: functions, expression and clinical importance. FEBS Lett. 2004 Mar 26;562(1):11-5.

21. Kampinga HH, Hageman J, Vos MJ, Kubota H, Tanguay RM, Bruford EA, et al. Guidelines for the nomenclature of the human heat shock proteins. Cell Stress Chaperones. 2009 Jan 1;14(1):105-11.

22. Li J, Soroka J, Buchner J. The Hsp90 chaperone machinery: Conformational dynamics and regulation by co-chaperones. Biochim Biophys Acta BBA - Mol Cell Res. 2012 Mar $1 ; 1823(3): 624-35$.

23. Marzec M, Eletto D, Argon Y. GRP94: An HSP90-like protein specialized for protein folding and quality control in the endoplasmic reticulum. Biochim Biophys Acta BBA - Mol Cell Res.

24. Altieri DC, Stein GS, Lian JB, Languino LR. TRAP-1, the mitochondrial Hsp90. Biochim Biophys Acta BBA - Mol Cell Res. 2012 Mar 1;1823(3):767-73.

25. Binder RJ. Functions of heat shock proteins in pathways of the innate and adaptive immune system. J Immunol Baltim Md 1950. 2014 Dec 15;193(12):5765-71.

26. Hance MW, Nolan KD, Isaacs JS. The double-edged sword: conserved functions of extracellular hsp90 in wound healing and cancer. Cancers. 2014 May 6;6(2):1065-97.

27. Hunter MC, O’Hagan KL, Kenyon A, Dhanani KCH, Prinsloo E, Edkins AL. Hsp90 binds cancer cells. PloS One. 2014;9(1):e86842. 
28. Baker-Williams AJ, Hashmi F, Budzyński MA, Woodford MR, Gleicher S, Himanen SV, et al. Co-chaperones TIMP2 and AHA1 Competitively Regulate Extracellular HSP90:Client MMP2 Activity and Matrix Proteolysis. Cell Rep. 2019 Aug 13;28(7):1894-1906.e6.

29. Whitesell L, Lindquist SL. HSP90 and the chaperoning of cancer. Nat Rev Cancer. 2005 Oct;5(10):761-72.

30. Jackson SE. Hsp90: structure and function. Top Curr Chem. 2013;328:155-240.

31. Buchner J, Li J. Structure, Function and Regulation of the Hsp90 Machinery. Biomed J. 2013;36(3):106.

32. Prodromou C. The 'active life' of Hsp90 complexes. Biochim Biophys Acta BBA - Mol Cell Res. 2012 Mar 1;1823(3):614-23.

33. Röhl A, Rohrberg J, Buchner J. The chaperone Hsp90: changing partners for demanding clients. Trends Biochem Sci. 2013 May 1;38(5):253-62.

34. Blatch GL, Lässle M. The tetratricopeptide repeat: a structural motif mediating protein-protein interactions. BioEssays. 1999;21(11):932-9.

35. Prodromou C, Siligardi G, O’Brien R, Woolfson DN, Regan L, Panaretou B, et al. Regulation of Hsp90 ATPase activity by tetratricopeptide repeat (TPR)-domain co-chaperones. EMBO J.

36. Zuehlke A, Johnson JL. Hsp90 and co-chaperones twist the functions of diverse client proteins. Biopolymers. 2010;93(3):211-7.

37. Aoyagi S, Archer TK. Modulating molecular chaperone Hsp90 functions through reversible

38. Duval M, Le Bœuf F, Huot J, Gratton J-P. Src-mediated Phosphorylation of Hsp90 in Response to Vascular Endothelial Growth Factor (VEGF) Is Required for VEGF Receptor-2 Signaling to Endothelial NO Synthase. Mol Biol Cell. 2007 Sep 12;18(11):4659-68. Sep 1;112(5):1886-93. 
40. Yang Y, Rao R, Shen J, Tang Y, Fiskus W, Nechtman J, et al. Role of Acetylation and Extracellular Location of Heat Shock Protein 90 $\alpha$ in Tumor Cell Invasion. Cancer Res. 2008 Jun 15;68(12):4833-42.

41. Citri A, Kochupurakkal BS, Yarden Y. The Achilles Heel of ErbB-2/HER2: Regulation by the Hsp90 Chaperone Machine and Potential for Pharmacological Intervention. Cell Cycle. 2004 Jan;3(1):50-9.

42. Porter JR, Fritz CC, Depew KM. Discovery and development of Hsp90 inhibitors: a promising pathway for cancer therapy. Curr Opin Chem Biol. 2010 Jun 1;14(3):412-20.

43. Trepel J, Mollapour M, Giaccone G, Neckers L. Targeting the dynamic HSP90 complex in cancer. Nat Rev Cancer. 2010 Aug;10(8):537-49.

44. Graefe SEB, Wiesgigl M, Gaworski I, Macdonald A, Clos J. Inhibition of HSP90 in Trypanosoma cruzi Induces a Stress Response but No Stage Differentiation. Eukaryot Cell. 2002 Dec 1;1(6):936-43.

45. Pallavi R, Roy N, Nageshan RK, Talukdar P, Pavithra SR, Reddy R, et al. Heat Shock Protein 90 as a Drug Target against Protozoan Infections biochemical characterization of hsp90 from plasmodium falciparum and trypanosoma evansi and evaluation of its inhibitor as a candidate drug. J Biol Chem. 2010 Mar 12;285(49):37964-75.

46. Meyer KJ, Shapiro TA. Potent Antitrypanosomal Activities of Heat Shock Protein 90 Inhibitors In Vitro and In Vivo. J Infect Dis. 2013 Aug 1;208(3):489-99.

47. Meyer KJ, Caton E, Shapiro TA. Model System Identifies Kinetic Driver of Hsp90 Inhibitor Activity against African Trypanosomes and Plasmodium falciparum. Antimicrob Agents Chemother [Internet]. 2018 Aug 1 [cited 2020 Sep 8];62(8). Available from: https://aac.asm.org/content/62/8/e00056-18

48. Kaiser M, Maes L, Tadoori LP, Spangenberg T, Ioset J-R. Repurposing of the Open Access Malaria Box for Kinetoplastid Diseases Identifies Novel Active Scaffolds against Trypanosomatids. J Biomol Screen. 2015 Jun 1;20(5):634-45.

49. Folgueira C, Requena JM. A postgenomic view of the heat shock proteins in kinetoplastids. FEMS Microbiol Rev. 2007 Jul;31(4):359-77. 
50. Shonhai A, G. Maier A, M. Przyborski J, L. Blatch G. Intracellular Protozoan Parasites of Humans: The Role of Molecular Chaperones in Development and Pathogenesis. Protein Pept Lett. 2011 Feb 1;18(2):143-57.

51. Urményi TP, Silva R, Rondinelli E. The heat shock proteins of Trypanosoma cruzi. Subcell Biochem. 2014;74:119-35.

52. Ploeg LV der, Giannini SH, Cantor CR. Heat shock genes: regulatory role for differentiation in parasitic protozoa. Science. 1985 Jun 21;228(4706):1443-6.

53. Wiesgigl M, Clos J. The heat shock protein 90 of Leishmania donovani. Med Microbiol Immunol (Berl). 2001 Nov;190(1-2):27-31.

54. Roy N, Nageshan RK, Ranade S, Tatu U. Heat shock protein 90 from neglected protozoan parasites. Biochim Biophys Acta BBA - Mol Cell Res. 2012 Mar 1;1823(3):707-11.

55. Figueras MJ, Echeverria PC, Angel SO. Protozoan HSP90-heterocomplex: molecular interaction network and biological significance. Curr Protein Pept Sci. 2014 May;15(3):245-55.

56. Jones C, Anderson S, Singha UK, Chaudhuri M. Protein phosphatase 5 is required for Hsp90 function during proteotoxic stresses in Trypanosoma brucei. Parasitol Res. 2008 Apr;102(5):835-44.

57. Preußer C, Jaé N, Bindereif A. mRNA splicing in trypanosomes. Int J Med Microbiol. 2012 Oct 1;302(4):221-4.

58. Urbaniak MD, Guther MLS, Ferguson MAJ. Comparative SILAC proteomic analysis of Trypanosoma brucei bloodstream and procyclic lifecycle stages. PloS One. 2012;7(5):e36619.

59. Butter F, Bucerius F, Michel M, Cicova Z, Mann M, Janzen CJ. Comparative proteomics of two life cycle stages of stable isotope-labeled Trypanosoma brucei reveals novel components of the parasite's host adaptation machinery. Mol Cell Proteomics MCP. 2013 Jan;12(1):172-9.

60. Goos C, Dejung M, Janzen CJ, Butter F, Kramer S. The nuclear proteome of Trypanosoma brucei. PloS One. 2017;12(7):e0181884.

61. Gunasekera K, Wüthrich D, Braga-Lagache S, Heller M, Ochsenreiter T. Proteome remodelling during development from blood to insect-form Trypanosoma brucei quantified by SILAC and mass spectrometry. BMC Genomics. 2012 Oct 16;13:556. 
62. Panigrahi AK, Ogata Y, Zíková A, Anupama A, Dalley RA, Acestor N, et al. A comprehensive analysis of Trypanosoma brucei mitochondrial proteome. Proteomics. 2009 Jan;9(2):434-50.

63. Peikert CD, Mani J, Morgenstern M, Käser S, Knapp B, Wenger C, et al. Charting organellar importomes by quantitative mass spectrometry. Nat Commun. 2017 May 9;8:15272.

64. Acestor N, Zíková A, Dalley RA, Anupama A, Panigrahi AK, Stuart KD. Trypanosoma brucei mitochondrial respiratome: composition and organization in procyclic form. Mol Cell Proteomics MCP. 2011 Sep;10(9):M110.006908.

65. Acestor N, Panigrahi AK, Ogata Y, Anupama A, Stuart KD. Protein composition of Trypanosoma brucei mitochondrial membranes. Proteomics. 2009 Dec;9(24):5497-508.

66. DeGrasse JA, Chait BT, Field MC, Rout MP. High-yield isolation and subcellular proteomic characterization of nuclear and subnuclear structures from trypanosomes. Methods Mol Biol Clifton NJ. 2008;463:77-92.

67. Colasante C, Ellis M, Ruppert T, Voncken F. Comparative proteomics of glycosomes from bloodstream form and procyclic culture form Trypanosoma brucei brucei. Proteomics. 2006 Jun;6(11):3275-93.

68. Güther MLS, Urbaniak MD, Tavendale A, Prescott A, Ferguson MAJ. High-confidence glycosome proteome for procyclic form Trypanosoma brucei by epitope-tag organelle enrichment and SILAC proteomics. J Proteome Res. 2014 Jun 6;13(6):2796-806.

69. Broadhead R, Dawe HR, Farr H, Griffiths S, Hart SR, Portman N, et al. Flagellar motility is required for the viability of the bloodstream trypanosome. Nature. 2006 Mar 9;440(7081):2247.

70. Subota I, Julkowska D, Vincensini L, Reeg N, Buisson J, Blisnick T, et al. Proteomic analysis of intact flagella of procyclic Trypanosoma brucei cells identifies novel flagellar proteins with unique sub-localization and dynamics. Mol Cell Proteomics MCP. 2014 Jul;13(7):1769-86.

71. Shimogawa MM, Saada EA, Vashisht AA, Barshop WD, Wohlschlegel JA, Hill KL. Cell Surface Proteomics Provides Insight into Stage-Specific Remodeling of the Host-Parasite Interface in Trypanosoma brucei. Mol Cell Proteomics MCP. 2015 Jul;14(7):1977-88.

72. Backe SJ, Sager RA, Woodford MR, Makedon AM, Mollapour M. Post-translational modifications of Hsp90 and translating the chaperone code. J Biol Chem. 2020 Aug 7;295(32):11099-117. 
73. Moretti NS, Cestari I, Anupama A, Stuart K, Schenkman S. Comparative Proteomic Analysis of Lysine Acetylation in Trypanosomes. J Proteome Res. 2018 Jan 5;17(1):374-85.

74. Nett IRE, Davidson L, Lamont D, Ferguson MAJ. Identification and Specific Localization of Tyrosine-Phosphorylated Proteins in Trypanosoma brucei. Eukaryot Cell. 2009 Apr;8(4):61726.

75. Nett IRE, Martin DMA, Miranda-Saavedra D, Lamont D, Barber JD, Mehlert A, et al. The phosphoproteome of bloodstream form Trypanosoma brucei, causative agent of African sleeping sickness. Mol Cell Proteomics MCP. 2009 Jul;8(7):1527-38.

76. Urbaniak MD, Martin DMA, Ferguson MAJ. Global quantitative SILAC phosphoproteomics reveals differential phosphorylation is widespread between the procyclic and bloodstream form lifecycle stages of Trypanosoma brucei. J Proteome Res. 2013 May 3;12(5):2233-44.

77. Zhang N, Jiang N, Zhang K, Zheng L, Zhang D, Sang X, et al. Landscapes of Protein Posttranslational Modifications of African Trypanosoma Parasites. iScience [Internet]. 2020 Apr 18 [cited 2020 Sep 17];23(5). Available from: https://www.ncbi.nlm.nih.gov/pmc/articles/PMC7218301/

78. Aslett M, Aurrecoechea C, Berriman M, Brestelli J, Brunk BP, Carrington M, et al. TriTrypDB: a functional genomic resource for the Trypanosomatidae. Nucleic Acids Res. 2010 Jan;38(Database issue):D457-62.

79. Letunic I, Doerks T, Bork P. SMART 7: recent updates to the protein domain annotation resource. Nucleic Acids Res. 2012 Jan 1;40(D1):D302-5.

80. Sigrist CJA, Cerutti L, de Castro E, Langendijk-Genevaux PS, Bulliard V, Bairoch A, et al. PROSITE, a protein domain database for functional characterization and annotation. Nucleic Acids Res. 2010 Jan 1;38(suppl_1):D161-6.

81. Larkin MA, Blackshields G, Brown NP, Chenna R, McGettigan PA, McWilliam H, et al. Clustal W and Clustal X version 2.0. Bioinformatics. 2007 Nov 1;23(21):2947-8.

82. Kumar S, Stecher G, Li M, Knyaz C, Tamura K. MEGA X: Molecular Evolutionary Genetics Analysis across Computing Platforms. Battistuzzi FU, editor. Mol Biol Evol. 2018 Jun $1 ; 35(6): 1547-9$.

83. Jones DT, Taylor WR, Thornton JM. The rapid generation of mutation data matrices from protein sequences. Bioinformatics. 1992 Jun 1;8(3):275-82. 
1001

1002

1003

1004

1005

1006

1007

1008

1009

1010

1011

1012

1013

84. Gasteiger E, Hoogland C, Gattiker A, Duvaud S, Wilkins MR, Appel RD, et al. Protein Identification and Analysis Tools on the ExPASy Server. In: Walker JM, editor. The Proteomics Protocols Handbook [Internet]. Totowa, NJ: Humana Press; 2005 [cited 2020 Aug 7]. p. 571607. (Springer Protocols Handbooks). Available from: https://doi.org/10.1385/1-59259-890$0: 571$

85. Alsford S, Turner DJ, Obado SO, Sanchez-Flores A, Glover L, Berriman M, et al. Highthroughput phenotyping using parallel sequencing of RNA interference targets in the African trypanosome. Genome Res. 2011 Jun 1;21(6):915-24.

86. Gazestani VH, Yip CW, Nikpour N, Berghuis N, Salavati R. TrypsNetDB: An integrated framework for the functional characterization of trypanosomatid proteins. PLoS Negl Trop Dis. 2017 Feb 3;11(2):e0005368.

87. Dean S, Sunter JD, Wheeler RJ. TrypTag.org: A Trypanosome Genome-wide Protein Localisation Resource. Trends Parasitol. 2017 Feb;33(2):80-2.

88. Shaner NC, Lambert GG, Chammas A, Ni Y, Cranfill PJ, Baird MA, et al. A bright monomeric green fluorescent protein derived from Branchiostoma lanceolatum. Nat Methods. 2013 May;10(5):407-9.

89. Jackson AP, Sanders M, Berry A, McQuillan J, Aslett MA, Quail MA, et al. The Genome Sequence of Trypanosoma brucei gambiense, Causative Agent of Chronic Human African Trypanosomiasis. PLoS Negl Trop Dis. 2010 Apr 13;4(4):e658.

90. Gibson W. The origins of the trypanosome genome strains Trypanosoma brucei brucei TREU 927, T. b. gambiense DAL 972, T. vivax Y486 and T. congolense IL3000. Parasit Vectors. 2012 Apr 7;5(1):71.

91. Mottram JC, Murphy WJ, Agabian N. A transcriptional analysis of the Trypanosoma brucei hsp83 gene cluster. Mol Biochem Parasitol. 1989 Nov 1;37(1):115-27.

92. Dero B, Zampetti-Bosseler F, Pays E, Steinert M. The genome and the antigen gene repertoire of Trypanosoma brucei gambiense are smaller than those of T. b. brucei. Mol Biochem Parasitol. 1987 Dec;26(3):247-56.

93. Deschamps P, Lara E, Marande W, López-García P, Ekelund F, Moreira D. Phylogenomic analysis of kinetoplastids supports that trypanosomatids arose from within bodonids. Mol Biol Evol. 2011 Jan;28(1):53-8. 
94. Wallace FG. The trypanosomatid parasites of insects and arachnids. Exp Parasitol. 1966 Feb;18(1):124-93.

95. Gupta RS. Phylogenetic analysis of the $90 \mathrm{kD}$ heat shock family of protein sequences and an examination of the relationship among animals, plants, and fungi species. Mol Biol Evol. 1995 Nov 1;12(6):1063-73.

96. Emelyanov VV. Phylogenetic relationships of organellar Hsp90 homologs reveal fundamental differences to organellar Hsp70 and Hsp60 evolution. Gene. 2002 Oct 16;299(1):125-33.

97. Chen B, Piel WH, Gui L, Bruford E, Monteiro A. The HSP90 family of genes in the human genome: Insights into their divergence and evolution. Genomics. 2005 Dec 1;86(6):627-37.

98. Argon Y, Simen BB. GRP94, an ER chaperone with protein and peptide binding properties. Semin Cell Dev Biol. 1999 Oct 1;10(5):495-505.

99. Brandau S, Dresel A, Clos J. High constitutive levels of heat-shock proteins in humanpathogenic parasites of the genus Leishmania. Biochem J. 1995 Aug 15;310(1):225-32.

100. Drini S, Criscuolo A, Lechat P, Imamura H, Skalický T, Rachidi N, et al. Species- and StrainSpecific Adaptation of the HSP70 Super Family in Pathogenic Trypanosomatids. Genome Biol Evol. 2016 Jun 1;8(6):1980-95.

101. de Nadal E, Ammerer G, Posas F. Controlling gene expression in response to stress. Nat Rev Genet. 2011 Dec;12(12):833-45.

102. Clayton C, Shapira M. Post-transcriptional regulation of gene expression in trypanosomes and leishmanias. Mol Biochem Parasitol. 2007 Dec 1;156(2):93-101.

103. Requena $\mathrm{J}$ M. Lights and shadows on gene organization and regulation of gene expression in Leishmania. Front Biosci. 2011;16(1):2069.

104. Droll D, Minia I, Fadda A, Singh A, Stewart M, Queiroz R, et al. Post-Transcriptional Regulation of the Trypanosome Heat Shock Response by a Zinc Finger Protein. PLOS Pathog. 2013 Apr 4;9(4):e1003286.

105. Ooi CP, Benz C, Urbaniak MD. Phosphoproteomic analysis of mammalian infective Trypanosoma brucei subjected to heat shock suggests atypical mechanisms for thermotolerance. J Proteomics. 2020 May 15;219:103735. 
1051

1052

1053

1054

1055

1056

1057

1058

1059

1060

1061

1062

1063

1064

1065

1066

1067

1068

1069

106. Bente M, Harder S, Wiesgigl M, Heukeshoven J, Gelhaus C, Krause E, et al. Developmentally induced changes of the proteome in the protozoan parasite Leishmania donovani. PROTEOMICS. 2003;3(9):1811-29.

107. Hombach A, Ommen G, Chrobak M, Clos J. The Hsp90-Sti1 interaction is critical for Leishmania donovani proliferation in both life cycle stages. Cell Microbiol. 2013 Apr;15(4):585-600.

108. Pizarro JC, Hills T, Senisterra G, Wernimont AK, Mackenzie C, Norcross NR, et al. Exploring the Trypanosoma brucei Hsp83 potential as a target for structure guided drug design. PLoS Negl Trop Dis. 2013;7(10):e2492.

109. Nadeau K, Walsh CT, Bradley M, Sullivan MA, Engman DM. 83-Kilodalton heat shock proteins of trypanosomes are potent peptide-stimulated ATPases. Protein Sci. 1992;1(8):970-9.

110. Taldone T, Wang T, Rodina A, Pillarsetty NVK, Digwal CS, Sharma S, et al. A Chemical Biology Approach to the Chaperome in Cancer-HSP90 and Beyond. Cold Spring Harb Perspect Biol. 2020 Apr 1;12(4).

111. Hainzl O, Lapina MC, Buchner J, Richter K. The Charged Linker Region Is an Important Regulator of Hsp90 Function. J Biol Chem. 2009 Aug 21;284(34):22559-67.

112. Tsutsumi S, Mollapour M, Graf C, Lee C-T, Scroggins BT, Xu W, et al. Hsp90 charged-linker truncation reverses the functional consequences of weakened hydrophobic contacts in the $\mathrm{N}$ domain. Nat Struct Mol Biol. 2009 Nov;16(11):1141-7.

113. Tsutsumi S, Mollapour M, Prodromou C, Lee C-T, Panaretou B, Yoshida S, et al. Charged linker sequence modulates eukaryotic heat shock protein 90 (Hsp90) chaperone activity. Proc Natl Acad Sci. 2012 Feb 21;109(8):2937-42.

114. Miyata Y, Yahara I. The 90-kDa heat shock protein, HSP90, binds and protects casein kinase II from self-aggregation and enhances its kinase activity. J Biol Chem. 1992 May 4;267(10):70427.

115. Mollapour M, Tsutsumi S, Truman AW, Xu W, Vaughan CK, Beebe K, et al. Threonine 22 Phosphorylation Attenuates Hsp90 Interaction with Cochaperones and Affects Its Chaperone Activity. Mol Cell. 2011 Mar 18;41(6):672-81. 
116. Mollapour M, Neckers L. Post-translational modifications of Hsp90 and their contributions to chaperone regulation. Biochim Biophys Acta BBA - Mol Cell Res. 2012 Mar 1;1823(3):64855.

117. Hombach-Barrigah A, Bartsch K, Smirlis D, Rosenqvist H, MacDonald A, Dingli F, et al. Leishmania donovani $90 \mathrm{kD}$ Heat Shock Protein - Impact of Phosphosites on Parasite Fitness, Infectivity and Casein Kinase Affinity. Sci Rep. 2019 Dec;9(1):5074.

118. Song HY, Dunbar JD, Zhang YX, Guo D, Donner DB. Identification of a Protein with Homology to hsp90 That Binds the Type 1 Tumor Necrosis Factor Receptor. J Biol Chem. 1995 Feb 24;270(8):3574-81.

119. Siegelin MD, Dohi T, Raskett CM, Orlowski GM, Powers CM, Gilbert CA, et al. Exploiting the mitochondrial unfolded protein response for cancer therapy in mice and human cells. J Clin Invest. 2011 Apr 1;121(4):1349-60.

120. Cechetto JD, Gupta RS. Immunoelectron Microscopy Provides Evidence That Tumor Necrosis Factor Receptor-Associated Protein 1 (TRAP-1) Is a Mitochondrial Protein Which also Localizes at Specific Extramitochondrial Sites. Exp Cell Res. 2000 Oct;260(1):30-9.

121. Felts SJ, Owen BAL, Nguyen P, Trepel J, Donner DB, Toft DO. The hsp90-related Protein TRAP1 Is a Mitochondrial Protein with Distinct Functional Properties. J Biol Chem. 2000 Apr 2;275(5):3305-12.

122. Schleiff E, Becker T. Common ground for protein translocation: access control for mitochondria and chloroplasts. Nat Rev Mol Cell Biol. 2011 Jan;12(1):48-59.

123. Osellame LD, Blacker TS, Duchen MR. Cellular and molecular mechanisms of mitochondrial function. Best Pract Res Clin Endocrinol Metab. 2012 Dec 1;26(6):711-23.

124. Stechmann A, Cavalier-Smith T. Phylogenetic Analysis of Eukaryotes Using Heat-Shock Protein Hsp90. J Mol Evol. 2003 Oct 1;57(4):408-19.

125. Descoteaux A. LeishmaniaLPG3 encodes a GRP94 homolog required for phosphoglycan synthesis implicated in parasite virulence but not viability. EMBO J. 2002 Sep 2;21(17):445869.

126. Larreta R, Soto M, Alonso C, Requena JM. Leishmania infantum: Gene Cloning of the GRP94 Homologue, Its Expression as Recombinant Protein, and Analysis of Antigenicity. Exp Parasitol. 2000 Oct 1;96(2):108-15. 
127. Larreta R, Guzman F, Patarroyo ME, Alonso C, Requena JM. Antigenic properties of the Leishmania infantum GRP94 and mapping of linear B-cell epitopes. Immunol Lett. 2002 Mar 1;80(3):199-205.

128. Yao C, Donelson JE, Wilson ME. The major surface protease (MSP or GP63) of Leishmania sp. Biosynthesis, regulation of expression, and function. Mol Biochem Parasitol. 2003 Nov $1 ; 132(1): 1-16$.

129. Panaretou B. ATP binding and hydrolysis are essential to the function of the Hsp90 molecular chaperone invivo. EMBO J. 1998 Aug 17;17(16):4829-36.

130. Johnson JL, Brown C. Plasticity of the Hsp90 chaperone machine in divergent eukaryotic organisms. Cell Stress Chaperones. 2009 Jan;14(1):83-94.

131. Seraphim TV, Alves MM, Silva IM, Gomes FER, Silva KP, Murta SMF, et al. Low Resolution Structural Studies Indicate that the Activator of Hsp90 ATPase 1 (Aha1) of Leishmania braziliensis Has an Elongated Shape Which Allows Its Interaction with Both N- and M-Domains of Hsp90. PLoS ONE [Internet]. 2013 Jun 24 [cited 2020 Apr 6];8(6). Available from: https://www.ncbi.nlm.nih.gov/pmc/articles/PMC3691308/

132. Chua C-S, Low H, Sim T-S. Co-chaperones of Hsp90 in Plasmodium falciparum and their concerted roles in cellular regulation. Parasitology. 2014 Aug;141(9):1177-91.

133. Tatu U, Neckers L. Chaperoning parasitism: the importance of molecular chaperones in pathogen virulence. Parasitology. 2014 Aug;141(9):1123-6.

134. Smith JR, Workman P. Targeting CDC37: An alternative, kinase-directed strategy for disruption of oncogenic chaperoning. Cell Cycle. 2009 Feb;8(3):362-72.

135. Oberholzer M, Langousis G, Nguyen HT, Saada EA, Shimogawa MM, Jonsson ZO, et al. Independent Analysis of the Flagellum Surface and Matrix Proteomes Provides Insight into Flagellum Signaling in Mammalian-infectious Trypanosoma brucei. Mol Cell Proteomics. 2011 Oct;10(10):M111.010538.

136. Chang HC, Nathan DF, Lindquist S. In vivo analysis of the Hsp90 cochaperone Sti1 (p60). Mol Cell Biol. 1997 Jan 1;17(1):318.

137. Johnson BD, Schumacher RJ, Ross ED, Toft DO. Hop Modulates hsp70/hsp90 Interactions in Protein Folding. J Biol Chem. 1998 Feb 6;273(6):3679-86. 
138. Brinker A, Scheufler C, von der Mülbe F, Fleckenstein B, Herrmann C, Jung G, et al. Ligand Discrimination by TPR Domains: relevance and selectivity of eevd-recognition in hsp70·hop·hsp90 complexes. J Biol Chem. 2002 May 31;277(22):19265-75.

139. Odunuga OO, Hornby JA, Bies C, Zimmermann R, Pugh DJ, Blatch GL. Tetratricopeptide Repeat Motif-mediated Hsc70-mSTI1 Interaction: molecular characterization of the critical contacts for successful binding and specificity. J Biol Chem. 2003 Feb 28;278(9):6896-904.

140. Baindur-Hudson S, Edkins AL, Blatch GL. Hsp70/Hsp90 Organising Protein (Hop): Beyond Interactions with Chaperones and Prion Proteins. In: Blatch GL, Edkins AL, editors. The Networking of Chaperones by Co-chaperones: Control of Cellular Protein Homeostasis [Internet]. Cham: Springer International Publishing; 2015 [cited 2020 Sep 15]. p. 69-90. (Subcellular Biochemistry). Available from: https://doi.org/10.1007/978-3-319-11731-7_3

141. Kravats AN, Hoskins JR, Reidy M, Johnson JL, Doyle SM, Genest O, et al. Functional and physical interaction between yeast Hsp90 and Hsp70. Proc Natl Acad Sci. 2018 Mar 6;115(10):E2210-9.

142. Bhattacharya K, Weidenauer L, Luengo TM, Pieters EC, Echeverría PC, Bernasconi L, et al. The Hsp70-Hsp90 co-chaperone Hop/Stip1 shifts the proteostatic balance from folding towards degradation. Nat Commun. 2020 Dec;11(1):5975.

143. Scheufler C, Brinker A, Bourenkov G, Pegoraro S, Moroder L, Bartunik H, et al. Structure of TPR Domain-Peptide Complexes: Critical Elements in the Assembly of the Hsp70-Hsp90 Multichaperone Machine. Cell. 2000 Apr 14;101(2):199-210.

144. Nelson GM, Huffman H, Smith DF. Comparison of the carboxy-terminal DP-repeat region in the co-chaperones Hop and Hip. Cell Stress Chaperones. 2003;8(2):125-33.

145. Webb JR, Campos-Neto A, Skeiky YA, Reed SG. Molecular characterization of the heatinducible LmSTI1 protein of Leishmania major. Mol Biochem Parasitol. 1997 Nov;89(2):179_ 93.

146. Schmidt JC, Soares MJ, Goldenberg S, Pavoni DP, Krieger MA. Characterization of TcSTI-1, a homologue of stress-induced protein-1, in Trypanosoma cruzi. Mem Inst Oswaldo Cruz. 2011 Feb;106(1):70-7.

147. Cohen PTW. Novel protein serine/threonine phosphatases: Variety is the spice of life. Trends Biochem Sci. 1997 Jul;22(7):245-51. 
148. Chinkers M. Protein phosphatase 5 in signal transduction. Trends Endocrinol Metab. 2001 Jan $1 ; 12(1): 28-32$.

149. Golden T, Swingle M, Honkanen RE. The role of serine/threonine protein phosphatase type 5 (PP5) in the regulation of stress-induced signaling networks and cancer. Cancer Metastasis Rev. 2008 Jun 1;27(2):169-78.

150. Borthwick EB, Zeke T, Prescott AR, Cohen PTW. Nuclear localization of protein phosphatase 5 is dependent on the carboxy-terminal region. FEBS Lett. 2001;491(3):279-84.

151. Chen M-S, Silverstein AM, Pratt WB, Chinkers M. The Tetratricopeptide Repeat Domain of Protein Phosphatase 5 Mediates Binding to Glucocorticoid Receptor Heterocomplexes and Acts as a Dominant Negative Mutant. J Biol Chem. 1996 Dec 13;271(50):32315-20.

152. Anderson S, Jones C, Saha L, Chaudhuri M. Functional characterization of the serine/threonine protein phosphatase 5 from trypanosoma brucei. J Parasitol. 2006 Dec;92(6):1152-61.

153. Galat A. Peptidylprolyl Cis / Trans Isomerases (Immunophilins): Biological Diversity - Targets - Functions. Curr Top Med Chem. 2003 Aug 1;3(12):1315-47.

154. Pratt WB, Galigniana MD, Harrell JM, DeFranco DB. Role of hsp90 and the hsp90-binding immunophilins in signalling protein movement. Cell Signal. 2004 Aug;16(8):857-72.

155. Steiner JP, Haughey NJ. Immunophilin Ligands. In: Kompoliti K, Metman LV, editors. Encyclopedia of Movement Disorders [Internet]. Oxford: Academic Press; 2010 [cited 2020 Jun 4]. $\quad$ p. 66-8. Available http://www.sciencedirect.com/science/article/pii/B9780123741059002549

156. Yau W-L, Blisnick T, Taly J-F, Helmer-Citterich M, Schiene-Fischer C, Leclercq O, et al. Cyclosporin A Treatment of Leishmania donovani Reveals Stage-Specific Functions of Cyclophilins in Parasite Proliferation and Viability. Kelly BL, editor. PLoS Negl Trop Dis. 2010 Jun 29;4(6):e729.

157. Yau W-L, Pescher P, MacDonald A, Hem S, Zander D, Retzlaff S, et al. The L eishmania donovani chaperone cyclophilin 40 is essential for intracellular infection independent of its stage-specific phosphorylation status: LdCyP40 null mutant analysis. Mol Microbiol. 2014 Jul;93(1):80-97.

158. Ratajczak T, Ward B, Minchin R. Immunophilin Chaperones in Steroid Receptor Signalling. Curr Top Med Chem. 2003 Aug 1;3(12):1348-57. 
159. Murthy AE, Bernards A, Church D, Wasmuth J, Gusella JF. Identification and Characterization of Two Novel Tetratricopeptide Repeat-Containing Genes. DNA Cell Biol. 1996 Sep;15(9):727-35.

160. Brychzy A, Rein T, Winklhofer KF, Hartl FU, Young JC, Obermann WMJ. Cofactor Tpr2 combines two TPR domains and a J domain to regulate the Hsp70/Hsp90 chaperone system. EMBO J. 2003 Jul 15;22(14):3613-23.

161. Moffatt NSC, Bruinsma E, Uhl C, Obermann WMJ, Toft D. Role of the cochaperone Tpr2 in Hsp90 chaperoning. Biochemistry. 2008 Aug 5;47(31):8203-13.

162. Leznicki P, High S. SGTA antagonizes BAG6-mediated protein triage. Proc Natl Acad Sci. 2012 Nov 20;109(47):19214-9.

163. Wunderley L, Leznicki P, Payapilly A, High S. SGTA regulates the cytosolic quality control of hydrophobic substrates. J Cell Sci. 2014 Nov 1;127(21):4728-39.

164. Roberts JD, Thapaliya A, Martínez-Lumbreras S, Krysztofinska EM, Isaacson RL. Structural and Functional Insights into Small, Glutamine-Rich, Tetratricopeptide Repeat Protein Alpha. Front Mol Biosci [Internet]. 2015 Dec 18 [cited 2020 Oct 21];2. Available from: http://journal.frontiersin.org/Article/10.3389/fmolb.2015.00071/abstract

165. Ommen G, Chrobak M, Clos J. The co-chaperone SGT of Leishmania donovani is essential for the parasite's viability. Cell Stress Chaperones. 2010 Jul;15(4):443-55.

166. Coto ALS, Seraphim TV, Batista FAH, Dores-Silva PR, Barranco ABF, Teixeira FR, et al. Structural and functional studies of the Leishmania braziliensis SGT co-chaperone indicate that it shares structural features with HIP and can interact with both Hsp90 and Hsp70 with similar affinities. Int J Biol Macromol. 2018 Oct 15;118:693-706.

167. Young JC. Polypeptide release by Hsp90 involves ATP hydrolysis and is enhanced by the cochaperone p23. EMBO J. 2000 Nov 1;19(21):5930-40.

168. McLaughlin SH, Sobott F, Yao Z, Zhang W, Nielsen PR, Grossmann JG, et al. The Cochaperone p23 Arrests the Hsp90 ATPase Cycle to Trap Client Proteins. J Mol Biol. 2006 Feb 24;356(3):746-58.

169. Bose S, Weikl T, Bugl H, Buchner J. Chaperone Function of Hsp90-Associated Proteins. Science. 1996 Dec 6;274(5293):1715-7. 
170. Freeman BC, Toft DO, Morimoto RI. Molecular Chaperone Machines: Chaperone Activities of the Cyclophilin Cyp-40 and the Steroid Aporeceptor-Associated Protein p23. Science. 1996 Dec 6;274(5293):1718-20.

171. Batista FAH, Almeida GS, Seraphim TV, Silva KP, Murta SMF, Barbosa LRS, et al. Identification of two p23 co-chaperone isoforms in Leishmania braziliensis exhibiting similar structures and Hsp90 interaction properties despite divergent stabilities. FEBS J. 2015;282(2):388-406.

172. Mayer MP, Nikolay R, Bukau B. Aha, Another Regulator for Hsp90 Chaperones. Mol Cell. 2002 Dec 1;10(6):1255-6.

173. Retzlaff M, Hagn F, Mitschke L, Hessling M, Gugel F, Kessler H, et al. Asymmetric Activation of the Hsp90 Dimer by Its Cochaperone Aha1. Mol Cell. 2010 Feb 12;37(3):344-54.

174. Koulov AV, LaPointe P, Lu B, Razvi A, Coppinger J, Dong M-Q, et al. Biological and Structural Basis for Aha1 Regulation of Hsp90 ATPase Activity in Maintaining Proteostasis in the Human Disease Cystic Fibrosis. Mol Biol Cell. 2010 Jan 20;21(6):871-84.

175. Urbaniak MD, Guther MLS, Ferguson MAJ. Comparative SILAC Proteomic Analysis of Trypanosoma brucei Bloodstream and Procyclic Lifecycle Stages. Li Z, editor. PLoS ONE. 2012 May 4;7(5):e36619.

176. Richter K, Reinstein J, Buchner J. A Grp on the Hsp90 Mechanism. Mol Cell. 2007 Oct;28(2):177-9.

177. Masgras I, Sanchez-Martin C, Colombo G, Rasola A. The Chaperone TRAP1 As a Modulator of the Mitochondrial Adaptations in Cancer Cells. Front Oncol [Internet]. 2017 Mar 29 [cited 2020 Oct 22];7. Available from: http://journal.frontiersin.org/article/10.3389/fonc.2017.00058/full

178. Radli M, Rüdiger SGD. Picky Hsp90-Every Game with Another Mate. Mol Cell. 2017 Sep 21;67(6):899-900.

179. Sahasrabudhe P, Rohrberg J, Biebl MM, Rutz DA, Buchner J. The Plasticity of the Hsp90 Cochaperone System. Mol Cell. 2017 Sep;67(6):947-961.e5.

180. Parsons M, Worthey EA, Ward PN, Mottram JC. Comparative analysis of the kinomes of three pathogenic trypanosomatids: Leishmania major, Trypanosoma brucei and Trypanosoma cruzi. BMC Genomics. 2005 Sep 15;6:127. 


\section{Supporting information}

1250

Fig S1. Alignment of the Hsp90/HSPC complement from T. brucei in relation to human and other selected kinetoplastids.

Multiple sequence alignment of the full-length amino acid sequences was performed using the in-built ClustalW program (81) with default parameters in the MEGA X software (82). Degree of amino acid conservation is symbolized by the following: $\left(^{*}\right)$ all fully conserved residues; (:) one of the residues is fully conserved and (.) residues are weakly conserved. The C-terminus motifs are empty-boxed in magenta for the cytosolic Hsp90. Residues involved in post translational modifications accordingly with MS PTM's proteomic studies by Nett et al, (2009b) and Zhang et al, (2020) coloured red for acetylation and yellow for phosphorylation. The red and yellow empty-boxed sites are highlighting conserved modified residues. Accession numbers for the Hsp90/HSPC amino acid sequences used in this study are provided in Table S1

Table S1. Accession numbers for the Hsp90/HSPC proteins in T. brucei and their respective orthologues in kinetoplastid parasites and $H$. sapiens

${ }^{a}$ The accession IDs for the members of the H. sapiens Hsp90/HSPC protein family were retrieved from NCBI (https://www.ncbi.nlm.nih.gov/).

${ }^{b}$ The accession IDs for the members of the T. b. brucei (Tb refers to Tbb), T. b. gambiense, T. cruzi, C. fasciculata, B. saltans and L. major Hsp90/HSPC protein family were retrieved from the TriTrypDB database (http://tritrypdb.org/tritrypdb/; Aslett et al. 2010).

c The accession IDs for the orthologues, identified by reciprocal BLASTP analysis, of three strains of $T$. cruzi are listed. T. cruzi CL Brener Esmeraldo-like (TcCLB), T. cruzi Dm28c 2018 (C4B63), and T. cruzi marinkelli strain B7 (Tc_MARK). 


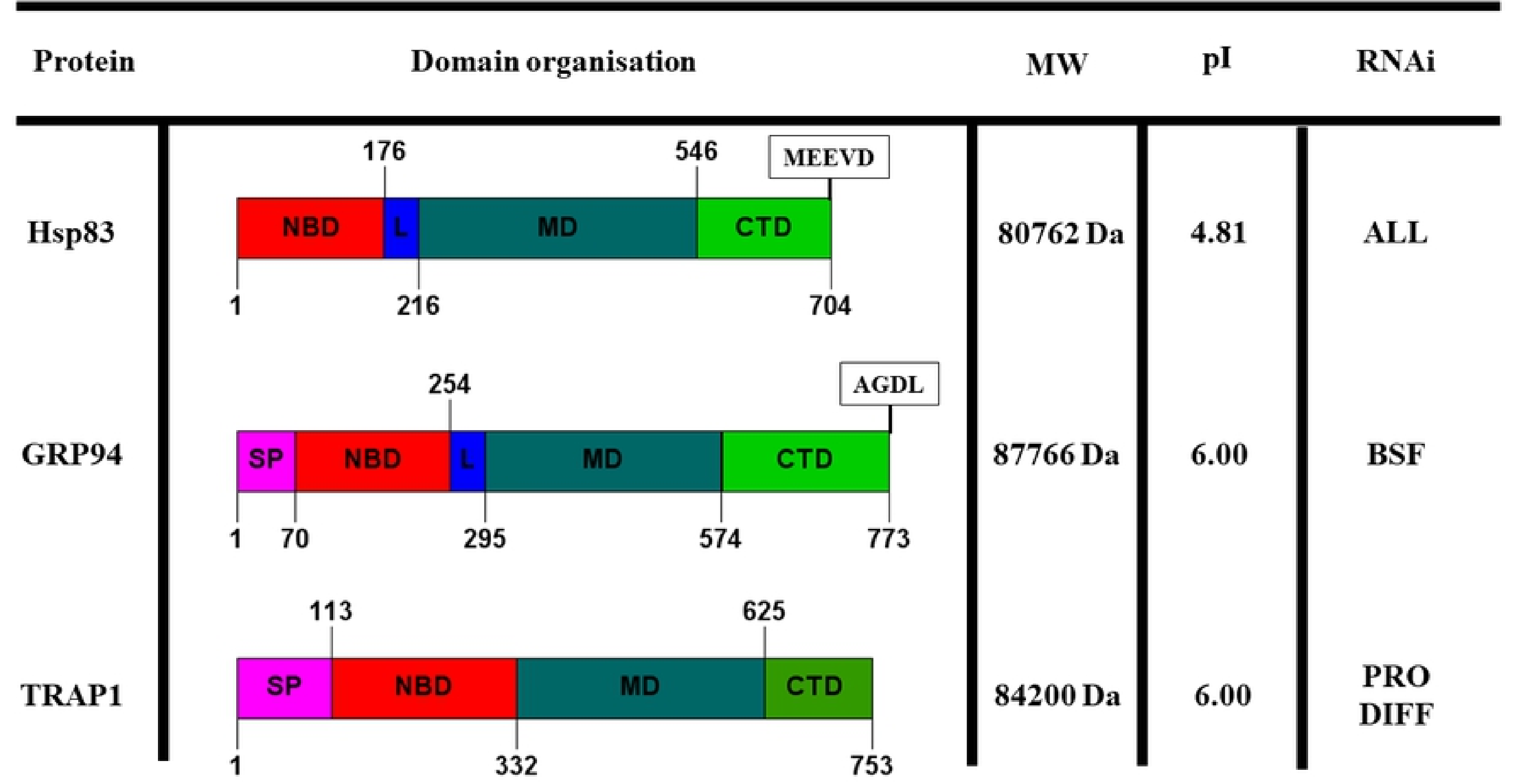

Figure 1 


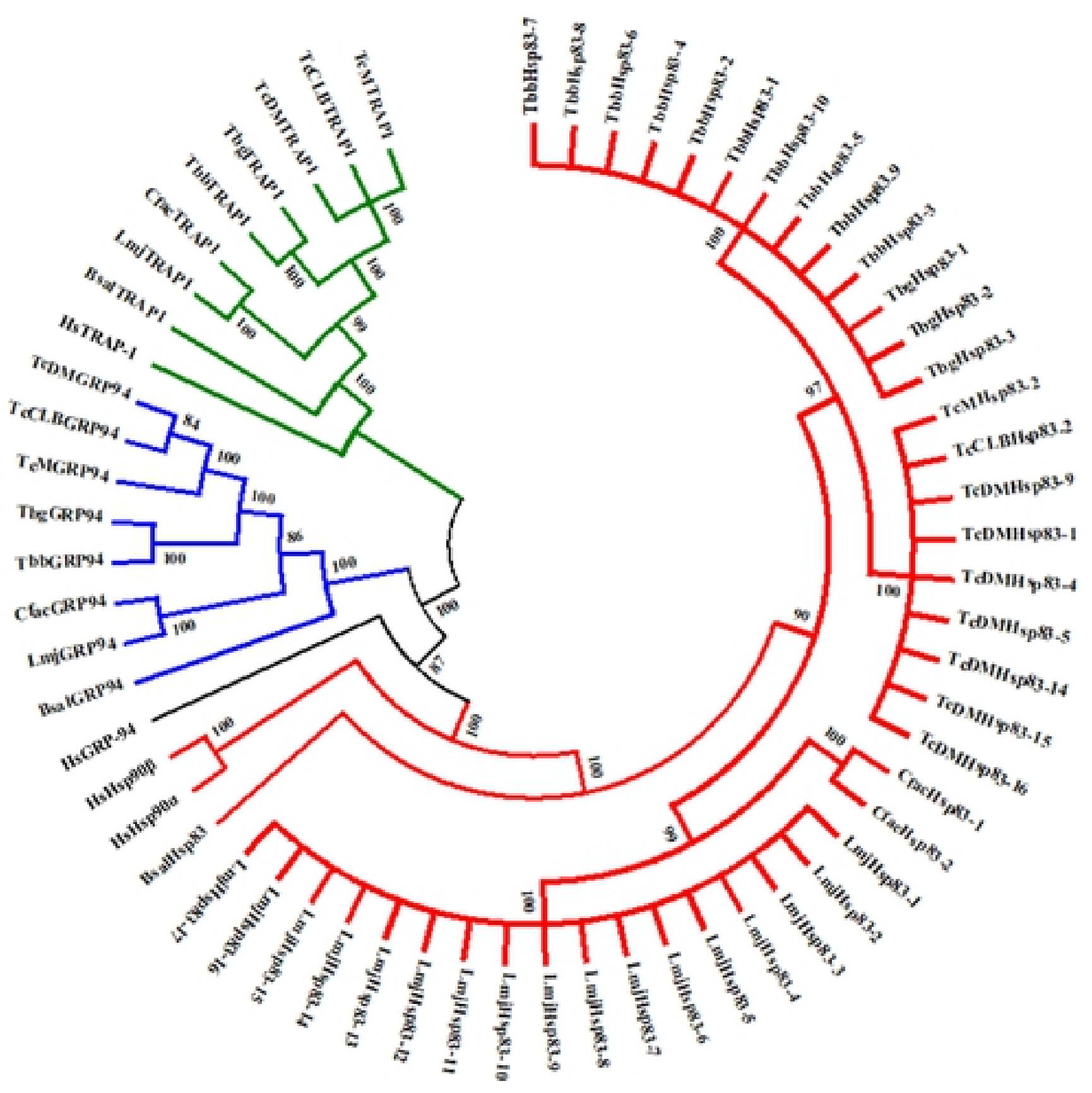

Figure 2 


\begin{tabular}{|c|c|c|c|c|}
\hline Protein & Domain organisation & MW & pl & RNAi \\
\hline STi & & $62327 \mathrm{Da}$ & 6.23 & BSF \\
\hline PP5 & & $53312 \mathrm{Da}$ & 6.61 & ND \\
\hline Cyp40 & & $38094 \mathrm{Da}$ & 6.26 & NE \\
\hline J52 & & $55926 \mathrm{Da}$ & 8.04 & BSF \\
\hline FKBPL & & $47604 \mathrm{Da}$ & 5.83 & ND \\
\hline Protein & Domain organisation & MW & pI & RNAi \\
\hline SGT & $m-\infty$ & $45966 \mathrm{Da}$ & 4.9 & ALL \\
\hline p23a & & $18768 \mathrm{Da}$ & 4.02 & $\begin{array}{l}\text { BSF } \\
\text { PRO }\end{array}$ \\
\hline p23b & & $21808 \mathrm{Da}$ & 4.17 & DIFF \\
\hline Ahal & $\mathrm{Cr}$ & $37612 \mathrm{Da}$ & 5.51 & BSF \\
\hline
\end{tabular}

Figure 4 